\title{
Território e Desenvolvimento em Karl Polanyi: uma revisão sistemática
}

\author{
Waldecy Rodrigues \\ Universidade Federal do Tocantins - Palmas - TO - Brasil \\ ORCID: https://orcid.org/0000-0002-5584-6586 \\ Wainesten Camargo \\ Universidade Federal do Tocantins - Palmas - TO - Brasil \\ ORCID: https://orcid.org/0000-0001-6290-9277
}

\begin{abstract}
Resumo
Este trabalho consiste em uma revisão sistemática da literatura acerca do desenvolvimento econômico territorial na perspectiva das obras de Karl Polanyi. Primeiramente, foi criado um protocolo para ordenar a seleção dos artigos científicos, para então ser realizada uma análise dos principais trabalhos que usaram Karl Polanyi, na perspectiva do desenvolvimento territorial, de modo central em suas abordagens. As principais bases de dados utilizadas foram SCOPUS, WEB OF SCIENCE e SCIELO, no período de 1990 a 2018. Foram encontrados cerca de 100 (cem) trabalhos que atenderam ao protocolo da revisão sistemática. Todos esses trabalhos foram lidos e seus detalhes podem ser encontrados no presente texto. Foi identificado que Karl Polanyi utiliza a abordagem clássica do território, e suas ideias mais abordadas são o duplo movimento, o enraizamento e a história econômica. Os principais resultados apontam para força do pensamento polanyiano em pesquisas sobre desenvolvimento em diversas escalas territoriais, permitindo pensar essas questões em termos interdisciplinares e plurais.
\end{abstract}

Palavras-chave: Karl Polanyi. Desenvolvimento. Território. Desenvolvimento Territorial. Revisão Sistemática.

\section{Abstract}

Territory and Development in Karl Polanyi Perspective: a systematic review

This paper consists of a systematic review of the literature on territorial economic development from the perspective of Karl Polanyi's works. For this, a protocol was created to order the selection of scientific articles, after this step, an analysis of the main works that used Karl Polanyi ideas, on the perspective from territorial development, in a central way in their approaches was performed. The main databases used were SCOPUS, WEB OF SCIENCE and SCIELO, from 1990 to 2018. About 100 (one hundred) papers were found that met the protocol of the systematic review. All these works have been read and their details and characteristics can be found in this text. It was identified that Karl Polanyi has a classical approach to territory, and his most discussed ideas are the double movement, embeddedness, and economic history. The main results point to the strength of Karl Polanyi thought in research on development in several territorial scales, allowing to think these issues in interdisciplinary and plural terms. 
Keywords: Karl Polanyi. Territory. Development. Territorial Development. Systematic Review.

\section{Resumen}

\section{Territorio y Desarrollo en Karl Polanyi: una revisión sistemática}

Este artículo consiste en una revisión sistemática de la literatura sobre desarrollo económico territorial desde la perspectiva de las obras de Karl Polanyi. Para esto, se creó un protocolo para ordenar la selección de artículos científicos, después de lo cual se realizó un análisis de los principales trabajos que han utilizado Karl Polanyi, desde la perspectiva del del desarrollo territorial, de una manera central en sus enfoques. Las principales bases de datos utilizadas fueron SCOPUS, WEB OF SCIENCE y SCIELO, de 1990 a 2018. Se encontraron alrededor de 100 (cien) artículos que cumplían con el protocolo de la revisión sistemática. Todos estos trabajos han sido leídos y sus detalles y características están disponibles en este texto. Se identificó el enfoque clásico de Karl Polanyi al territorio, así como sus ideas más discutidas: el doble movimiento, el enraizamiento y la historia económica. Los principales resultados apuntan a la fuerza del pensamiento de Karl Polanyi en la investigación sobre el desarrollo en varias escalas territoriales, lo que permite pensar estas en términos interdisciplinarios y plurales.

Palabras clave: Karl Polanyi. Desarrollo. Territorio. Desarrollo territorial. Revisión sistemática.

\section{Introdução}

Karl Polanyi, nascido em Vienna em 1886, desde que migrou para os Estados Unidos em meados da década de 1940 se dedicou a estudar economia em sua perspectiva histórica e institucional, buscando compreender os fenômenos sociais de sua época em um contexto estrutural. A abordagem polanyiana sobre o desenvolvimento sempre foi tida como marginal nas ciências sociais. Recentemente no Brasil, Schneider e Escher (2011), Rodrigues e Santos (2016; 2017) demonstraram a importância de retomar as ideias seminais de Polanyi para pesquisas que discutem os processos desenvolvimento em suas múltiplas escalas e dimensões, a partir de uma perspectiva holística e interdisciplinar.

Em “A Grande Transformação”, 2012a, Karl Polanyi lançou luz, não apenas calor, sobre as mudanças estruturais no aspecto político e econômico que se refletiram nas maiores guerras já testemunhadas pela humanidade e demais transformações da primeira metade do século XX. No primeiro capítulo dessa obra, Karl Polanyi apresenta que "A civilização do século XIX se firmava em quatro instituições [...] o sistema de equilíbrio de poder, [...] o padrão internacional do ouro, [...] o mercado autor regulável, [...] o estado liberal." (POLANYI, 2012a, p.3)

Setenta e cinco anos depois, novas transformações transmutam as organizações políticas e sociais. A revolução tecnológica vivida nas primeiras décadas do século XXI trouxe mudanças vorazes no equilíbrio de poder global e as formas de trabalho sofreram diversas transformações, que perturbaram as organizações sociais e políticas da época em que se escreve. Época esta muito semelhante ao que se vive neste início de milênio, com várias transformações tecnológicas, principalmente no campo das tecnologias da informação, porém com muitos riscos ambientais, sociais e de saúde pública globais. Nunca o homem na história, pela evolução das tecnologias da informação, esteve tão próximo, mas por 
outro lado está tão distante de si mesmo na busca pela paz e pelo desenvolvimento equilibrado e harmônico.

Diante disso, planejar ações de desenvolvimento torna-se um desafio, que exige um arcabouço teórico sofisticado para minimizar os riscos dos processos de transformação dos espaços em que são aplicadas. Para essa atividade, é necessário articular os aspectos da natureza humana com seu aspecto social.

No presente trabalho, para atender essa demanda, foi escolhido trabalhar Karl Polanyi, por entender que suas ideias explicam muitas das situações que ocorrem na sociedade deste século. Todavia, a observação de nosso momento histórico apresenta um cenário distinto desse, ocorrendo mudanças repentinas, ampliação dos níveis de incertezas e riscos, além do recrudescimento de ideologias que há muito pareciam estar enterradas pela história, mas surgem com vigor, evidenciando uma liquidez estarrecedora (BAUMAN, 2007).

Por isso, nesta revisão sistemática sobre o desenvolvimento econômico e o território em Karl Polanyi é apresentado o trajeto percorrido para selecionar os textos que abordam as ideias de Karl Polanyi, a forma de construção do protocolo de revisão, os instrumentos utilizados para a busca dos trabalhos, os dados sobre os trabalhos, e.g., se possuem aspecto teórico ou aplicado, o idioma em que estão escritos, o país de vínculo dos autores, as principais ideias de Karl Polanyi abordadas no trabalho.

O presente artigo se apresenta da seguinte forma, no item 2 deste artigo, o aspecto teórico do método que envolve uma revisão sistemática, os procedimentos observados para construção do protocolo de pesquisa, os trabalhos encontrados e revisados, e os resumos dos trabalhos selecionados. É uma seção eminentemente procedimental, para aqueles interessados na metodologia utilizada. Caso

Por fim, no item 3, as considerações finais apresentadas para encerramento do trabalho também cumprem o papel de resultado da revisão sistemática, assim, completando o método e concluindo o artigo.

\section{Metodologia}

Conforme exposto, a presente revisão sistemática buscou identificar publicações envolvendo desenvolvimento e território que trabalhem a obra de Karl Polanyi de modo central nas discussões, vez que isso possibilitará os interessados nas abordagens polaynianas vislumbrarem os trabalhos que têm sido produzidos discutindo o pensamento de Karl Polanyi, além de identificarem as principais ideias desse autor, favorecendo o estabelecimento de redes de intercâmbio e troca de experiências.

Ademais, uma revisão sistemática permite uma visão macro do cenário posto, assim, permitindo a consolidação de trabalhos estruturais, esses que frequentemente são os promotores de mudanças de paradigmas nas ciências humanas e sociais.

\subsection{Revisão sistemática: o método}

A revisão sistemática foi adotada inicialmente na área da Saúde no final da década de 1980, pois se observou um vasto número de publicações produzidas sem 
uma metodologia científica apropriada. Assim, o grande número de publicações gerou a necessidade de sintetizar as evidências, produzindo resultados advindos do confronto/combinação de diferentes outros resultados. (FELIZARDO; MARTINS, 2015).

Ademais, o termo 'revisão sistemática' pode ser utilizado de duas maneiras, tanto para descrever a metodologia científica em si mesma quanto para referir-se ao produto obtido pelo emprego desse método. Para isso, identificando e filtrando estudos relevantes e os avaliando por meio de critérios pré-definidos, o que distingue uma revisão tradicional de uma revisão sistemática.

Outrossim, a revisão sistemática permite trabalhar de forma mais objetiva com grande quantidade de informações, contribuindo para a catalogação das que se enquadram ou não para atender demandas específicas, identificando trabalhos não significativos ou irrelevantes, assim, como consequência, apontando nichos de pesquisas necessárias (PETTICREW; ROBERTS, 2006).

Para isso, conforme expõe Torgerson, 2003, a revisão sistemática pode ser dividida em estágios:

I - Um protocolo ou plano de pesquisa é produzido para estabelecer o contexto teórico, empírico e conceitual à revisão, além dos objetivos, o escopo e os métodos de pesquisa, visualização e extração de dados, avaliação de qualidade e síntese;

II- Uma vez determinado o protocolo, são especificados os critérios de inclusão e exclusão de trabalhos na lista a ser analisada;

III - Superadas as questões de protocolo, se inicia a pesquisa por trabalhos que se incluam no escopo do projeto, essa primeira busca é feita de forma digital, sempre catalogando o material encontrado. Nessa fase, é sugerida a participação de pares independentes para evitar qualquer viés;

IV- No estágio de catalogação, os trabalhos são descritos e catalogados. Nesse estágio todos os trabalhos terão suas informações arquivadas para uma revisão posterior mais aprofundada, onde serão aplicados os filtros de classificação dispostos no protocolo;

$V$ - Identificados os trabalhos relevantes, suas informações devem ser extraídas de forma padronizada, recomendando a participação de dois pesquisadores independentes nessa atividade;

$\mathrm{VI}$ - As informações extraídas são resumidas em sínteses;

VII - Por último, as informações são sintetizadas e interpretadas, gerando relatório que pode ser revisado por pares antes da publicação.

\subsection{Procedimentos utilizados na revisão sistemática}

Nesta revisão sistemática foi utilizado o portal de periódicos do Conselho Aperfeiçoamento de Pessoal de Nível Superior - CAPES, pois, por meio desse portal é possível pesquisar e acessar periódicos nos principais indexadores de produção científica.

Em fase preparatória da presente revisão sistemática foram propostas buscas nos seguintes idiomas: alemão, chinês, espanhol, inglês, francês, português, russo e árabe. Todavia, em buscas preliminares, constatou-se que as buscas em alemão, chinês, russo e árabe não seriam frutíferas, pois não foram obtidos 
retornos que atendessem ao protocolo da revisão, desse modo, a revisão foi realizada com buscas em inglês, francês, espanhol e português.

A seguinte tabela apresenta os radicais escolhidos e utilizados na construção das strings de busca.

Quadro 1. Strings de busca utilizadas na revisão sistemática

\begin{tabular}{|c|}
\hline no título polany* and no título territ* \\
\hline no título polany* and no assunto territ* \\
\hline no título territ* and no assunto polany* \\
\hline no assunto polany* and no assunto territ* \\
\hline no título polany* and no título regi* \\
\hline no título polany* and no assunto regi* \\
\hline no título regi* and no assunto polany* \\
\hline no assunto polany* and no assunto regi* \\
\hline no título polany* and no título desenv* \\
\hline no título polany* and no assunto desenv* \\
\hline no título desenv* and no assunto polany* \\
\hline no assunto polany* and no assunto desenv* \\
\hline no título polany* and no título desarr* \\
\hline no título polany* and no assunto desarr* \\
\hline no título desarr* and no assunto polany* \\
\hline no assunto polany* and no assunto desarr* \\
\hline no título polany* and no título develop* \\
\hline no título polany* and no assunto develop* \\
\hline no título develop** and no assunto polany* \\
\hline no assunto polany* and no assunto develop* \\
\hline
\end{tabular}

Os asteriscos foram colocados para que a ferramenta de busca compreendesse se tratar do radical da palavra de interesse, não necessariamente a palavra em si. Após essa busca, foram realizados procedimentos de exclusão de informações não concernentes às buscas esperadas.

Após esses procedimentos, para seguir com a catalogação dos trabalhos, foram organizados os 95 (noventa e cinco) trabalhos restantes, para análise da revisão sistemática, sendo eles:

Quadro 2. Trabalhos para Análise da Revisão Sistemática

\begin{tabular}{|c|c|c|c|c|c|c|c|c|}
\hline AUTORIA & TíTULO & ANO & DIVULGAÇÃo & IDIOMA & $\begin{array}{l}\text { PAíS DO } \\
\text { VíNCULO }\end{array}$ & ABORDAGEM & ASPECTO & CATEGORIA \\
\hline $\begin{array}{l}\text { ADAMAN, } \\
\text { Fikret; } \\
\text { DEVINE, } \\
\text { Pat; } \\
\text { OZKAYNAK, } \\
\text { Begum. } \\
\end{array}$ & $\begin{array}{l}\text { Reinstituting the Economic } \\
\text { Process: (Re)embedding the } \\
\text { Economy in Society and } \\
\text { Nature }\end{array}$ & 2003 & \begin{tabular}{|c|}
\multicolumn{1}{c|}{ International } \\
$\quad$ Review of \\
Sociology / Revue \\
Internationale de \\
Sociologie
\end{tabular} & Inglês & $\begin{array}{c}\text { Turquia / } \\
\text { Reino Unido } \\
\text { / Espanha }\end{array}$ & Enraizamento & Teórico & Sociedade \\
\hline $\begin{array}{l}\text { AKTURK, } \\
\text { Sener. }\end{array}$ & $\begin{array}{l}\text { Between Aristotle and the } \\
\text { Welfare State: The } \\
\text { Establishment, Enforcement, } \\
\text { and Transformation of the } \\
\text { Moral Economy in Karl } \\
\text { Polanyi's The Great } \\
\text { Transformation }\end{array}$ & 2006 & $\begin{array}{c}\text { Theoria: A Journal } \\
\text { of Social and } \\
\text { Political Theory }\end{array}$ & Inglês & N.I. & Liberdade & Teórico & Sociedade \\
\hline \begin{tabular}{|l} 
ALTVATER, \\
Elmar; \\
MAHNKOP \\
F, Birgit. \\
\end{tabular} & The World Market Unbound & 1997 & $\begin{array}{c}\text { Review of } \\
\text { International } \\
\text { Political Economy }\end{array}$ & Inglês & Alemanha & Enraizamento & Teórico & Econômica \\
\hline $\begin{array}{l}\text { AMIN, } \\
\text { Samir. }\end{array}$ & $\begin{array}{c}\text { The Challenge of } \\
\text { Globalization }\end{array}$ & 1996 & \begin{tabular}{|c|} 
Review of \\
International \\
Political Economy \\
\end{tabular} & Inglês & Senegal & $\begin{array}{l}\text { História } \\
\text { Econômica }\end{array}$ & Teórico & Econômica \\
\hline
\end{tabular}




\begin{tabular}{|c|c|c|c|c|c|c|c|c|}
\hline AUTORIA & TítUlo & ANO & DIVULGAÇÃO & IDIOMA & $\begin{array}{l}\text { PAÍS DO } \\
\text { VÍNCULO } \\
\end{array}$ & ABORDAGEM & ASPECTO & CATEGORIA \\
\hline $\begin{array}{l}\text { BARBER, } \\
\text { Bernard. }\end{array}$ & $\begin{array}{c}\text { All Economies Are } \\
\text { "Embedded": The Career of a } \\
\text { Concept, and Beyond }\end{array}$ & 1995 & Social Research & Inglês & N.I. & Enraizamento & Teórico & Sociedade \\
\hline $\begin{array}{l}\text { BENERIA, } \\
\text { Lourdes. } \\
\end{array}$ & $\begin{array}{c}\text { Globalization, Gender and the } \\
\text { Davos Man }\end{array}$ & 1999 & $\begin{array}{c}\text { Feminist } \\
\text { Economics }\end{array}$ & Inglês & $\begin{array}{l}\text { Estados } \\
\text { Unidos }\end{array}$ & $\begin{array}{c}\text { História } \\
\text { Econômica }\end{array}$ & Teórico & Gênero \\
\hline \begin{tabular}{|c|} 
BENITES- \\
LAZARO, \\
Lira Luz; \\
MELLO- \\
THÉRY, Neli \\
Aparecida. \\
\end{tabular} & $\begin{array}{l}\text { CSR as a legitimatizing tool in } \\
\text { carbon market: Evidence from } \\
\text { Latin America's Clean } \\
\text { Development Mechanism }\end{array}$ & 2017 & $\begin{array}{c}\text { Journal of Cleaner } \\
\text { Production }\end{array}$ & Inglês & Brasil & $\begin{array}{l}\text { Duplo } \\
\text { Movimento }\end{array}$ & Aplicado & $\begin{array}{c}\text { Meio } \\
\text { Ambiente }\end{array}$ \\
\hline $\begin{array}{l}\text { BERGER, } \\
\text { Sebastian. }\end{array}$ & $\begin{array}{c}\text { Karl Polanyi's and Karl William } \\
\text { Kapp's substantive } \\
\text { economics: important insights } \\
\text { from the Kapp-Polanyi } \\
\text { correspondence }\end{array}$ & 2008 & $\begin{array}{c}\text { Review of Social } \\
\text { Economy }\end{array}$ & Inglês & $\begin{array}{l}\text { Estados } \\
\text { Unidos }\end{array}$ & $\begin{array}{l}\text { História } \\
\text { Econômica }\end{array}$ & Teórico & Sociedade \\
\hline $\begin{array}{c}\text { BIRCHFIELD } \\
\text {, Vicki }\end{array}$ & $\begin{array}{c}\text { Contesting the hegemony of } \\
\text { market ideology: Gramsci's' } \\
\text { good sense'and Polanyi's' } \\
\text { double movement' }\end{array}$ & 1999 & $\begin{array}{c}\text { Review of } \\
\text { International } \\
\text { Political Economy }\end{array}$ & Inglês & $\begin{array}{l}\text { Estados } \\
\text { Unidos }\end{array}$ & $\begin{array}{l}\text { Duplo } \\
\text { Movimento }\end{array}$ & Teórico & Econômico \\
\hline $\begin{array}{l}\text { BLOCK, } \\
\text { Fred }\end{array}$ & $\begin{array}{c}\text { A Neo- Polanyian Theory of } \\
\text { Economic Crises }\end{array}$ & 2015 & $\begin{array}{c}\text { American Journal } \\
\text { of Economics and } \\
\text { Sociology }\end{array}$ & Inglês & $\begin{array}{l}\text { Estados } \\
\text { Unidos }\end{array}$ & $\begin{array}{l}\text { História } \\
\text { Econômica }\end{array}$ & Teórico & Econômico \\
\hline $\begin{array}{l}\text { BLYTH, } \\
\text { Mark }\end{array}$ & $\begin{array}{c}\text { The Great Transformation in } \\
\text { Understanding Polanyi: Reply } \\
\text { to Hejeebu and McCloskey }\end{array}$ & 2004 & Critical Review & Inglês & $\begin{array}{l}\text { Estados } \\
\text { Unidos }\end{array}$ & $\begin{array}{l}\text { História } \\
\text { Econômica }\end{array}$ & Teórico & Sociedade \\
\hline $\begin{array}{l}\text { BOND, } \\
\text { Patrick }\end{array}$ & $\begin{array}{l}\text { Gramsci, Polanyi and } \\
\text { Impressions from Africa on } \\
\text { the Social Forum } \\
\text { Phenomenon } \\
\end{array}$ & 2005 & $\begin{array}{c}\text { International } \\
\text { Journal of Urban } \\
\text { and Regional } \\
\text { Research } \\
\end{array}$ & Inglês & África do Sul & $\begin{array}{l}\text { História } \\
\text { Econômica }\end{array}$ & Teórico & Sociedade \\
\hline $\begin{array}{c}\text { BURAWOY, } \\
\text { Michael }\end{array}$ & $\begin{array}{c}\text { Transition without } \\
\text { transformation: Russia's } \\
\text { involutionary road to } \\
\text { capitalism } \\
\end{array}$ & 2001 & $\begin{array}{l}\text { East European } \\
\text { Politics and } \\
\text { Societies }\end{array}$ & Inglês & N.I. & $\begin{array}{c}\text { Duplo } \\
\text { Movimento }\end{array}$ & Aplicado & Econômico \\
\hline $\begin{array}{l}\text { CANGIANI, } \\
\text { Michele }\end{array}$ & The Forgotten Institution & 2003 & \begin{tabular}{|c|} 
International \\
Review of \\
Sociology/Revue \\
Internationale de \\
Sociologie \\
\end{tabular} & Inglês & Itália & $\begin{array}{l}\text { História } \\
\text { Econômica }\end{array}$ & Teórico & Econômico \\
\hline $\begin{array}{l}\text { CANGIANI, } \\
\text { Michele }\end{array}$ & $\begin{array}{l}\text { Veblen's critique of political } \\
\text { economy }\end{array}$ & 2004 & \begin{tabular}{|c|} 
International \\
Review of \\
Sociology/Revue \\
Internationale de \\
Sociologie \\
\end{tabular} & Inglês & Itália & $\begin{array}{l}\text { História } \\
\text { Econômica }\end{array}$ & Teórico & Econômico \\
\hline $\begin{array}{l}\text { CANGIANI, } \\
\text { Michele }\end{array}$ & The unknown Karl Polanyi & 2009 & \begin{tabular}{|c|} 
International \\
Review of \\
Sociology/Revue \\
Internationale de \\
Sociologie \\
\end{tabular} & Inglês & Itália & Outros & Teórico & Sociedade \\
\hline $\begin{array}{l}\text { CANGIANI, } \\
\text { Michele }\end{array}$ & $\begin{array}{l}\text { Karl Polanyi's Institutional } \\
\text { Theory: Market Society and } \\
\text { Its" Disembedded" Economy }\end{array}$ & 2011 & $\begin{array}{c}\text { Journal of } \\
\text { Economic Issues }\end{array}$ & Inglês & Itália & $\begin{array}{l}\text { História } \\
\text { Econômica }\end{array}$ & Teórico & Econômico \\
\hline $\begin{array}{l}\text { CARROLL, } \\
\text { Myles }\end{array}$ & $\begin{array}{l}\text { The new agrarian double } \\
\text { movement: Hegemony and } \\
\text { resistance in the GMO food } \\
\text { economy }\end{array}$ & 2016 & $\begin{array}{c}\text { Review of } \\
\text { International } \\
\text { Political Economy }\end{array}$ & Inglês & Canadá & $\begin{array}{l}\text { Duplo } \\
\text { Movimento }\end{array}$ & Teórico & $\begin{array}{l}\text { Meio } \\
\text { Ambiente }\end{array}$ \\
\hline $\begin{array}{l}\text { CARROLL, } \\
\text { Michael C. }\end{array}$ & $\begin{array}{l}\text { Social Capital, Karl Polanyi, } \\
\text { and American Social and } \\
\text { Institutional Economics }\end{array}$ & 2003 & $\begin{array}{c}\text { Journal of } \\
\text { Economic Issues }\end{array}$ & Inglês & $\begin{array}{l}\text { Estados } \\
\text { Unidos }\end{array}$ & Enraizamento & Teórico & Sociedade \\
\hline $\begin{array}{c}\text { CíSAR, } \\
\text { Ondrej; } \\
\text { NAVRÁTIL, } \\
\text { Jirí }\end{array}$ & $\begin{array}{l}\text { Polanyi, political-economic } \\
\text { opportunity structure and } \\
\text { protest: capitalism and } \\
\text { contention in the post- } \\
\text { communist Czech Republic }\end{array}$ & 2017 & $\begin{array}{c}\text { Social Movement } \\
\text { Studies }\end{array}$ & Inglês & $\begin{array}{l}\text { República } \\
\text { Checa }\end{array}$ & $\begin{array}{l}\text { Duplo } \\
\text { Movimento }\end{array}$ & Aplicado & Econômico \\
\hline $\begin{array}{c}\text { COPESTAKE } \\
\text {, James }\end{array}$ & $\begin{array}{l}\text { The global financial crisis of } \\
\text { 2008-2009: an opportunity } \\
\text { for development studies? }\end{array}$ & 2010 & $\begin{array}{c}\text { Journal of } \\
\text { International } \\
\text { Development }\end{array}$ & Inglês & Reino Unido & $\begin{array}{l}\text { História } \\
\text { Econômica }\end{array}$ & Teórico & Econômico \\
\hline $\begin{array}{l}\text { COTULA, } \\
\text { Lorenzo }\end{array}$ & $\begin{array}{c}\text { The New Enclosures? Polanyi, } \\
\text { international investment law } \\
\text { and the global land rush }\end{array}$ & 2013 & $\begin{array}{l}\text { Third World } \\
\text { Quarterly }\end{array}$ & Inglês & Reino Unido & $\begin{array}{l}\text { História } \\
\text { Econômica }\end{array}$ & Teórico & Econômico \\
\hline $\begin{array}{l}\text { CRAIG, } \\
\text { David; } \\
\text { PORTER, } \\
\text { Doug. }\end{array}$ & $\begin{array}{l}\text { The third way and the third } \\
\text { world: poverty reduction and } \\
\text { social inclusion strategies in } \\
\text { the rise of 'inclusive' } \\
\text { liberalism }\end{array}$ & 2005 & $\begin{array}{c}\text { Review of } \\
\text { International } \\
\text { Political Economy }\end{array}$ & Inglês & $\begin{array}{l}\text { Austrália / } \\
\text { Filipinas }\end{array}$ & $\begin{array}{c}\text { Duplo } \\
\text { Movimento }\end{array}$ & Teórico & Econômico \\
\hline
\end{tabular}




\begin{tabular}{|c|c|c|c|c|c|c|c|c|}
\hline AUTORIA & TíTULO & ANO & DIVULGAÇÃO & IDIOMA & $\begin{array}{l}\text { PAÍS DO } \\
\text { VÍNCULO }\end{array}$ & ABORDAGEM & ASPECTO & CATEGORIA \\
\hline $\begin{array}{l}\text { CUADRA, } \\
\text { Héctor }\end{array}$ & $\begin{array}{c}\text { Polanyi mestizo Una } \\
\text { interpretación de los } \\
\text { procesos sociales de Estado y } \\
\text { mercado en México/Half-cast } \\
\text { Polanyi Social Processes of } \\
\text { State and Market in Mexico: } \\
\text { An Interpretation }\end{array}$ & 2015 & $\begin{array}{c}\text { Revista mexicana } \\
\text { de ciencias } \\
\text { políticas y sociales }\end{array}$ & Espanhol & México & $\begin{array}{l}\text { História } \\
\text { Econômica }\end{array}$ & Aplicado & Econômico \\
\hline $\begin{array}{l}\text { DALE, } \\
\text { Gareth }\end{array}$ & $\begin{array}{l}\text { Lineages of embeddedness: } \\
\text { on the antecedents and } \\
\text { successors of a Polanyian } \\
\text { concept. }\end{array}$ & 2011 & $\begin{array}{c}\text { American Journal } \\
\text { of Economics and } \\
\text { Sociology }\end{array}$ & Inglês & Reino Unido & Enraizamento & Teórico & Sociedade \\
\hline $\begin{array}{l}\text { DALE, } \\
\text { Gareth }\end{array}$ & $\begin{array}{c}\text { The iron law of democratic } \\
\text { socialism: British and Austrian } \\
\text { influences on the young Karl } \\
\text { Polanyi }\end{array}$ & 2014 & $\begin{array}{l}\text { Economy and } \\
\text { Society }\end{array}$ & Inglês & Reino Unido & Outros & Teórico & Político \\
\hline $\begin{array}{l}\text { DODD, } \\
\text { Steven }\end{array}$ & $\begin{array}{c}\text { Orientating disability studies } \\
\text { to disablist austerity: applying } \\
\text { Fraser's insights }\end{array}$ & 2016 & $\begin{array}{l}\text { Disability \& } \\
\text { Society }\end{array}$ & Inglês & Reino Unido & Enraizamento & Teórico & Saúde \\
\hline $\begin{array}{l}\text { DYMSKI, } \\
\text { Gary A. }\end{array}$ & $\begin{array}{c}\text { Polanyi, Minsky y el problema } \\
\text { del Orden Monetario Global: } \\
\text { de las altas finanzas a los } \\
\text { megabancos }\end{array}$ & 2014 & $\begin{array}{l}\text { Revista Ola } \\
\text { Financiera }\end{array}$ & Inglês & Reino Unido & $\begin{array}{l}\text { Duplo } \\
\text { Movimento }\end{array}$ & Teórico & Econômico \\
\hline $\begin{array}{l}\text { ESPINOZA, } \\
\text { Iván V. }\end{array}$ & $\begin{array}{c}\text { Karl Polanyi y la teoría social } \\
\text { en América Latina: avances, } \\
\text { desarrollos y desafíos } \\
\text { actuales }\end{array}$ & 2016 & $\begin{array}{c}\text { Polis. Revista } \\
\text { Latinoamericana }\end{array}$ & Espanhol & Chile & $\begin{array}{l}\text { História } \\
\text { Econômica }\end{array}$ & Teórico & Econômico \\
\hline $\begin{array}{l}\text { FINDLAY, } \\
\text { Mark }\end{array}$ & $\begin{array}{c}\text { Masking neo-liberal } \\
\text { development: Polanyi, rule of } \\
\text { law and dis-embedding } \\
\text { dynamics }\end{array}$ & 2017 & $\begin{array}{l}\text { International } \\
\text { Journal of } \\
\text { Development } \\
\text { Issues, }\end{array}$ & Inglês & Singapura & Enraizamento & Teórico & Econômico \\
\hline $\begin{array}{l}\text { FONTAN, } \\
\text { Jean-Marc }\end{array}$ & $\begin{array}{l}\text { Développement territorial et } \\
\text { innovation sociale : l'apport } \\
\text { polanyien }\end{array}$ & 2008 & \begin{tabular}{|c|} 
Revue \\
Interventions \\
économiques. \\
Papers in Political \\
Economy
\end{tabular} & francês & Canadá & $\begin{array}{l}\text { História } \\
\text { Econômica }\end{array}$ & Teórico & Econômico \\
\hline $\begin{array}{l}\text { FRASER, } \\
\text { Nancy }\end{array}$ & $\begin{array}{l}\text { Can society be commodities } \\
\text { all the way down? Post- } \\
\text { Polanyian reflections on } \\
\text { capitalist crisis }\end{array}$ & 2014 & $\begin{array}{l}\text { Economy and } \\
\text { Society }\end{array}$ & Inglês & $\begin{array}{l}\text { Estados } \\
\text { Unidos }\end{array}$ & $\begin{array}{l}\text { História } \\
\text { Econômica }\end{array}$ & Teórico & Econômico \\
\hline $\begin{array}{l}\text { GIRÓN, } \\
\text { Alicia }\end{array}$ & $\begin{array}{c}\text { Austeridad, democracia y } \\
\text { financiarización: Relevancia } \\
\text { de K. Polanyi en una } \\
\text { economía monetaria de } \\
\text { producción en la post-crisis }\end{array}$ & 2015 & Análísís & Espanhol & México & Dinheiro & Teórico & Ecômica \\
\hline $\begin{array}{c}\text { GOODWIN, } \\
\text { Geoff }\end{array}$ & $\begin{array}{l}\text { Rethinking the Double } \\
\text { Movement: Expanding the } \\
\text { Frontiers of Polanyian } \\
\text { Analysis in the Global South }\end{array}$ & 2018 & $\begin{array}{c}\text { Development and } \\
\text { Change }\end{array}$ & Inglês & Reino Unido & $\begin{array}{l}\text { Duplo } \\
\text { Movimento }\end{array}$ & Teórico & Econômico \\
\hline \begin{tabular}{|c|} 
GRADDY- \\
LOVELACE, \\
Garrett; \\
DIAMOND, \\
Adam. \\
\end{tabular} & $\begin{array}{l}\text { From supply management to } \\
\text { agricultural subsidies-and } \\
\text { back again? The US Farm Bill } \\
\text { \& agrarian (in) viability }\end{array}$ & 2017 & $\begin{array}{l}\text { Journal of rural } \\
\text { studies }\end{array}$ & Inglês & $\begin{array}{l}\text { Estados } \\
\text { Unidos }\end{array}$ & $\begin{array}{c}\text { Duplo } \\
\text { Movimento }\end{array}$ & Aplicado & Rural \\
\hline $\begin{array}{c}\text { GUTHMAN, } \\
\text { Julie }\end{array}$ & $\begin{array}{c}\text { The Polanyian Way? Voluntary } \\
\text { Food Labels as Neoliberal } \\
\text { Governance }\end{array}$ & 2007 & Antipode & Inglês & $\begin{array}{l}\text { Estados } \\
\text { Unidos }\end{array}$ & $\begin{array}{l}\text { Duplo } \\
\text { Movimento }\end{array}$ & Teórico & Sociedade \\
\hline $\begin{array}{c}\text { HADDORFF, } \\
\text { David }\end{array}$ & $\begin{array}{l}\text { Religion and the Market: } \\
\text { Opposition, Absorption, or } \\
\text { Ambiguity? }\end{array}$ & 2000 & $\begin{array}{c}\text { Review of Social } \\
\text { Economy }\end{array}$ & Inglês & $\begin{array}{l}\text { Estados } \\
\text { Unidos }\end{array}$ & $\begin{array}{l}\text { Duplo } \\
\text { Movimento }\end{array}$ & Teórico & Sociedade \\
\hline $\begin{array}{c}\text { HARRISS, } \\
\text { John }\end{array}$ & $\begin{array}{l}\text { Institutions, Politics and } \\
\text { Culture: A Polanyian } \\
\text { Perspective on Economic } \\
\text { Change }\end{array}$ & 2003 & \begin{tabular}{|c|} 
International \\
Review of \\
Sociology/Revue \\
Internationale de \\
Sociologie \\
\end{tabular} & Inglês & Reino Unido & $\begin{array}{l}\text { História } \\
\text { Econômica }\end{array}$ & Teórico & Sociedade \\
\hline \begin{tabular}{|c|} 
HEJEEBU, \\
Santhi; \\
MCCLOSKE \\
Y, Deirdre. \\
\end{tabular} & The Reproving of Karl Polanyi & 1999 & Critical Review & Inglês & $\begin{array}{l}\text { Estados } \\
\text { Unidos }\end{array}$ & $\begin{array}{l}\text { História } \\
\text { Econômica }\end{array}$ & Teórico & Sociedade \\
\hline $\begin{array}{l}\text { HEJEEBU, } \\
\text { Santhi; } \\
\text { MCCLOSKE } \\
\text { Y, Deirdre. }\end{array}$ & $\begin{array}{c}\text { Polanyi and the History of } \\
\text { Capitalism: Rejoinder to Blyth }\end{array}$ & 2004 & Critical Review & Inglês & $\begin{array}{l}\text { Estados } \\
\text { Unidos }\end{array}$ & $\begin{array}{l}\text { História } \\
\text { Econômica }\end{array}$ & Teórico & Sociedade \\
\hline $\begin{array}{l}\text { HESS, } \\
\text { Martin }\end{array}$ & $\begin{array}{l}\text { 'Spatial'relationships? } \\
\text { Towards a } \\
\text { reconceptualization of } \\
\text { embedded ness }\end{array}$ & 2004 & $\begin{array}{l}\text { Progress in } \\
\text { human } \\
\text { geography }\end{array}$ & Inglês & Alemanha & Enraizamento & Teórico & Sociedade \\
\hline
\end{tabular}




\begin{tabular}{|c|c|c|c|c|c|c|c|c|}
\hline AUTORIA & TíTULO & ANO & DIVULGAÇÃO & IDIOMA & $\begin{array}{l}\text { PAÍS DO } \\
\text { VÍNCULO }\end{array}$ & ABORDAGEM & ASPECTO & CATEGORIA \\
\hline $\begin{array}{l}\text { HODGSON, } \\
\text { Geoffrey M. }\end{array}$ & $\begin{array}{c}\begin{array}{c}\text { Karl Polanyi on economy and } \\
\text { society: a critical analysis of } \\
\text { core concepts }\end{array} \\
\end{array}$ & 2017 & $\begin{array}{c}\text { Review of Social } \\
\text { Economy }\end{array}$ & Inglês & Reino Unido & Enraizamento & Teórico & Sociedade \\
\hline $\begin{array}{l}\text { HOLMES, } \\
\text { Christopher }\end{array}$ & $\begin{array}{l}\text { 'Whatever it takes': Polanyian } \\
\text { perspectives on the eurozone } \\
\text { crisis and the gold standard }\end{array}$ & 2014 & $\begin{array}{l}\text { Economy and } \\
\text { Society }\end{array}$ & Inglês & Reino Unido & Dinheiro & Teórico & Econômico \\
\hline $\begin{array}{c}\text { HÖPNER, } \\
\text { Martin; } \\
\text { SCHÄFER, } \\
\text { Armin. } \\
\end{array}$ & $\begin{array}{l}\text { Embeddedness and Regional } \\
\text { Integration: Waiting for } \\
\text { Polanyi in a Hayekian Setting }\end{array}$ & 2012 & $\begin{array}{l}\text { International } \\
\text { Organization }\end{array}$ & Inglês & N.I. & $\begin{array}{l}\text { Duplo } \\
\text { Movimento }\end{array}$ & Teórico & Econômico \\
\hline $\begin{array}{l}\text { HOUGH, } \\
\text { Phillip A.; } \\
\text { BAIR, } \\
\text { Jennifer. }\end{array}$ & $\begin{array}{l}\text { Dispossession, Class } \\
\text { Formation, and the Political } \\
\text { Imaginary of Colombia's } \\
\text { Coffee Producers over the } \\
\text { Longue Duree: Beyond the } \\
\text { Polanyian Analytic }\end{array}$ & 2012 & $\begin{array}{l}\text { Journal of World- } \\
\text { Systems Research }\end{array}$ & Inglês & $\begin{array}{l}\text { Estados } \\
\text { Unidos }\end{array}$ & $\begin{array}{l}\text { Duplo } \\
\text { Movimento }\end{array}$ & Aplicado & Sociedade \\
\hline \begin{tabular}{|c|} 
JOHNSON, \\
Pauline
\end{tabular} & $\begin{array}{l}\text { The Embedded Market and } \\
\text { Ideology Critique }\end{array}$ & 2011 & Critical Horizons & Inglês & Austrália & Enraizamento & Teórico & Sociedade \\
\hline KIM, Wonik & $\begin{array}{l}\text { Simultaneous transitions: } \\
\text { Democratization, } \\
\text { neoliberalization, and } \\
\text { possibilities for class } \\
\text { compromise in South Korea }\end{array}$ & 2010 & \begin{tabular}{|} 
Review of Radical \\
Political \\
Economics
\end{tabular} & Inglês & $\begin{array}{l}\text { Estados } \\
\text { Unidos }\end{array}$ & $\begin{array}{l}\text { História } \\
\text { Econômica }\end{array}$ & Aplicado & Econômico \\
\hline $\begin{array}{l}\text { KIRBY, } \\
\text { Peadar }\end{array}$ & $\begin{array}{l}\text { The World Bank or Polanyi: } \\
\text { Markets, Poverty and Social } \\
\text { Well-Being in Latin America }\end{array}$ & 2002 & $\begin{array}{l}\text { New Political } \\
\text { Economy }\end{array}$ & Inglês & Irlanda & $\begin{array}{l}\text { História } \\
\text { Econômica }\end{array}$ & Teórico & Econômico \\
\hline $\begin{array}{l}\text { KIRBY, } \\
\text { Peadar }\end{array}$ & $\begin{array}{c}\text { Transforming Capitalism: The } \\
\text { Triple Crisis }\end{array}$ & 2013 & $\begin{array}{l}\text { Irish Journal of } \\
\text { Sociology }\end{array}$ & Inglês & Irlanda & $\begin{array}{c}\text { História } \\
\text { Econômica }\end{array}$ & Teórico & $\begin{array}{c}\text { Meio } \\
\text { Ambiente } \\
\end{array}$ \\
\hline $\begin{array}{l}\text { KNOWLES, } \\
\text { Rob; } \\
\text { OWEN, } \\
\text { John R. } \\
\end{array}$ & $\begin{array}{c}\text { Karl Polanyi for Historians: An } \\
\text { Alternative Economic } \\
\text { Narrative }\end{array}$ & 2008 & European Legacy & Inglês & Austrália & $\begin{array}{l}\text { História } \\
\text { Econômica }\end{array}$ & Teórico & Sociedade \\
\hline $\begin{array}{l}\text { KRIPPNER, } \\
\text { Greta R.; } \\
\text { ALVAREZ, } \\
\text { Anthony S. }\end{array}$ & $\begin{array}{l}\text { Embeddedness and the } \\
\text { Intellectual Projects of } \\
\text { Economic Sociology }\end{array}$ & 2007 & $\begin{array}{c}\text { Annual Review of } \\
\text { Sociology }\end{array}$ & Inglês & $\begin{array}{l}\text { Estados } \\
\text { Unidos }\end{array}$ & Enraizamento & Teórico & Sociedade \\
\hline $\begin{array}{l}\text { KRIPPNER, } \\
\text { Greta; } \\
\text { GRANOVET } \\
\text { TER, Mark; }\end{array}$ & $\begin{array}{l}\text { Polanyi Symposium: A } \\
\text { Conversation on } \\
\text { Embeddedness }\end{array}$ & 2004 & $\begin{array}{l}\text { Socio-economic } \\
\text { review. }\end{array}$ & Inglês & $\begin{array}{l}\text { Estados } \\
\text { Unidos / } \\
\text { Canadá / } \\
\text { Irlanda }\end{array}$ & Enraizamento & Teórico & Sociedade \\
\hline \begin{tabular}{|c|} 
LE GALES, \\
Patrick; \\
SCOTT, \\
Alan. \\
\end{tabular} & $\begin{array}{l}\text { The Remaking of the Market } \\
\text { Subject }\end{array}$ & 2009 & $\begin{array}{l}\text { Berliner journal } \\
\text { für Soziologie }\end{array}$ & Alemão & $\begin{array}{l}\text { França / } \\
\text { Austria }\end{array}$ & $\begin{array}{l}\text { História } \\
\text { Econômica }\end{array}$ & Teórico & Econômico \\
\hline \begin{tabular}{|c|} 
LEMAÎTRE, \\
Andreia; \\
HELMSING, \\
Albertus \\
Hendrikus \\
Johannes. \\
\end{tabular} & $\begin{array}{l}\text { Solidarity economy in Brazil: } \\
\text { movement, discourse and } \\
\text { practice analysis through a } \\
\text { Polanyian understanding of } \\
\text { the economy }\end{array}$ & 2012 & $\begin{array}{c}\text { Journal of } \\
\text { International } \\
\text { Development }\end{array}$ & Inglês & $\begin{array}{l}\text { Belgica / } \\
\text { Holanda }\end{array}$ & $\begin{array}{l}\text { História } \\
\text { Econômica }\end{array}$ & Teórico & Econômico \\
\hline \begin{tabular}{|c|} 
LEVI, Yair; \\
PELLEGRIN- \\
RESCIA, \\
Marie \\
Louise. \\
\end{tabular} & $\begin{array}{l}\text { A New Look at the } \\
\text { Embeddedness/Disembedded } \\
\text { ness Issue: Cooperatives as } \\
\text { Terms of Reference }\end{array}$ & 1997 & $\begin{array}{c}\text { The Journal of } \\
\text { Socio-Economics }\end{array}$ & Inglês & $\begin{array}{l}\text { Israel / } \\
\text { França }\end{array}$ & Enraizamento & Teórico & Econômico \\
\hline $\begin{array}{l}\text { LEVITT, Kari } \\
\text { Polanyi; } \\
\text { SECCARECC } \\
\text { IA, Mario. } \\
\end{array}$ & $\begin{array}{c}\text { Neoliberalismo: La } \\
\text { perspectiva polanyiana }\end{array}$ & 2018 & Ola Financiera & Espanhol & Canadá & $\begin{array}{l}\text { História } \\
\text { Econômica }\end{array}$ & Teórico & Econômico \\
\hline $\begin{array}{c}\begin{array}{c}\text { LOŠONC, } \\
\text { Alpar }\end{array} \\
\end{array}$ & $\begin{array}{c}\text { Karl Polanyi, the Transition, } \\
\text { and the Social Capital }\end{array}$ & 2004 & Sociologija & Sérvio & Sérvia & $\begin{array}{c}\text { História } \\
\text { Econômica } \\
\end{array}$ & Teórico & Econômico \\
\hline $\begin{array}{l}\text { MCGEE, } \\
\text { Jeffrey; } \\
\text { STEFFEK, } \\
\text { Jens. }\end{array}$ & $\begin{array}{l}\text { The Copenhagen Turn in } \\
\text { Global Climate Governance } \\
\text { and the Contentious History } \\
\text { of Differentiation in } \\
\text { International Law }\end{array}$ & 2016 & $\begin{array}{c}\text { Journal of } \\
\text { Environmental } \\
\text { Law }\end{array}$ & Inglês & $\begin{array}{l}\text { Austrália / } \\
\text { Alemanha }\end{array}$ & $\begin{array}{l}\text { Duplo } \\
\text { Movimento }\end{array}$ & Teórico & $\begin{array}{c}\text { Meio } \\
\text { Ambiente }\end{array}$ \\
\hline $\begin{array}{l}\text { MCMICHAE } \\
\text { L, Philip }\end{array}$ & $\begin{array}{l}\text { Rethinking Globalization: The } \\
\text { Agrarian Question Revisited }\end{array}$ & 1997 & \begin{tabular}{|c|} 
Review of \\
International \\
Political Economy \\
\end{tabular} & Inglês & $\begin{array}{l}\text { Estados } \\
\text { Unidos }\end{array}$ & $\begin{array}{l}\text { História } \\
\text { Econômica }\end{array}$ & Teórico & $\begin{array}{c}\text { Meio } \\
\text { Ambiente }\end{array}$ \\
\hline $\begin{array}{l}\text { MCMICHAE } \\
\text { L, Philip }\end{array}$ & $\begin{array}{l}\text { Reconsidering Globalization: } \\
\text { The Agrarian Question Once } \\
\text { More }\end{array}$ & 1998 & $\begin{array}{c}\text { Revista Mexicana } \\
\text { de Sociología }\end{array}$ & Espanhol & $\begin{array}{l}\text { Estados } \\
\text { Unidos }\end{array}$ & $\begin{array}{l}\text { História } \\
\text { Econômica }\end{array}$ & Teórico & $\begin{array}{c}\text { Meio } \\
\text { Ambiente }\end{array}$ \\
\hline $\begin{array}{l}\text { MINA, } \\
\text { Andrea }\end{array}$ & $\begin{array}{c}\text { The Creation of the European } \\
\text { Market for Mobile Telephony: } \\
\text { Overview of an Instituted } \\
\text { Process }\end{array}$ & 2003 & \begin{tabular}{|c|} 
International \\
Review of \\
Sociology/Revue \\
Internationale de \\
Sociologie \\
\end{tabular} & Inglês & Reino Unido & $\begin{array}{l}\text { História } \\
\text { Econômica }\end{array}$ & Teórico & Teconologia \\
\hline
\end{tabular}




\begin{tabular}{|c|c|c|c|c|c|c|c|c|}
\hline AUTORIA & TíTULO & ANO & DIVULGAÇÃO & IDIOMA & $\begin{array}{l}\text { PAÍS DO } \\
\text { VÍNCULO }\end{array}$ & ABORDAGEM & ASPECTO & CATEGORIA \\
\hline $\begin{array}{c}\text { MITTELMA } \\
\mathrm{N} \text {, James H. }\end{array}$ & $\begin{array}{c}\text { Globalisation and } \\
\text { Environmental Resistance } \\
\text { Politics } \\
\end{array}$ & 1998 & World Quarterly & Inglês & $\begin{array}{l}\text { Estados } \\
\text { Unidos }\end{array}$ & $\begin{array}{l}\text { História } \\
\text { Econômica }\end{array}$ & Aplicado & $\begin{array}{c}\text { Meio } \\
\text { Ambiente }\end{array}$ \\
\hline $\begin{array}{l}\text { MUNCK, } \\
\text { Ronaldo }\end{array}$ & $\begin{array}{c}\text { Karl Polanyi for Latin America: } \\
\text { markets, society and } \\
\text { development }\end{array}$ & 2015 & \begin{tabular}{|c|} 
Canadian Journal \\
of Development \\
Studies/Revue \\
canadienne \\
d'études du \\
développement
\end{tabular} & Inglês & Irlanda & $\begin{array}{l}\text { História } \\
\text { Econômica }\end{array}$ & Teórico & Econômico \\
\hline $\begin{array}{l}\text { NORTH, } \\
\text { Peter }\end{array}$ & $\begin{array}{l}\text { The business of the } \\
\text { Anthropocene? Substantivist } \\
\text { and diverse economies } \\
\text { perspectives on SME } \\
\text { engagement in local low } \\
\text { carbon transitions }\end{array}$ & 2016 & $\begin{array}{l}\text { Progress in } \\
\text { Human } \\
\text { Geography }\end{array}$ & Inglês & Reino Unido & $\begin{array}{l}\text { História } \\
\text { Econômica }\end{array}$ & Teórico & Econômico \\
\hline $\begin{array}{l}\text { ÖZGÜR, } \\
\text { Gökçer; } \\
\text { ÖZEL, } \\
\text { Hüseyin. }\end{array}$ & $\begin{array}{l}\text { Double movement, } \\
\text { globalization, and the crisis. }\end{array}$ & 2013 & $\begin{array}{c}\text { American Journal } \\
\text { of Economics and } \\
\text { Sociology }\end{array}$ & Inglês & Turquia & $\begin{array}{l}\text { Duplo } \\
\text { Movimento }\end{array}$ & Teórico & Econômico \\
\hline $\begin{array}{l}\text { PARK, } \\
\text { James W.; } \\
\text { PARK, } \\
\text { Martha } M .\end{array}$ & $\begin{array}{l}\text { The Altrurian Economics of } \\
\text { William Dean Howells: The } \\
\text { Novelists Criticisms of US } \\
\text { Capitalism Are Evaluated by } \\
\text { Karl Polanyi's Norms }\end{array}$ & 1990 & $\begin{array}{c}\text { American Journal } \\
\text { of Economics and } \\
\text { Sociology }\end{array}$ & Inglês & $\begin{array}{l}\text { Estados } \\
\text { Unidos }\end{array}$ & $\begin{array}{l}\text { História } \\
\text { Econômcia }\end{array}$ & Teórico & Econômico \\
\hline $\begin{array}{l}\text { PEARSE, } \\
\text { Rebecca }\end{array}$ & $\begin{array}{c}\text { Moving targets: Carbon } \\
\text { pricing, energy markets, and } \\
\text { social movements in Australia } \\
\end{array}$ & 2016 & $\begin{array}{l}\text { Environmental } \\
\text { politics }\end{array}$ & Inglês & Austrália & $\begin{array}{c}\text { Duplo } \\
\text { Movimento }\end{array}$ & Aplicado & Sociedade \\
\hline $\begin{array}{l}\text { PECK, } \\
\text { Jamie }\end{array}$ & Polanyi in the Pilbara & 2013 & $\begin{array}{c}\text { Australian } \\
\text { Geographer }\end{array}$ & Inglês & Canadá & $\begin{array}{c}\text { História } \\
\text { Econômica } \\
\end{array}$ & Aplicado & Econômico \\
\hline \begin{tabular}{|c|} 
PETTIFOR, \\
Ann
\end{tabular} & Brexit and its Consequences & 2017 & Globalizations & Inglês & Reino Unido & $\begin{array}{c}\text { Duplo } \\
\text { Movimento }\end{array}$ & Aplicado & Econômico \\
\hline $\begin{array}{l}\text { QUARK, } \\
\text { Amy; } \\
\text { LIENESCH, } \\
\text { Rachel. }\end{array}$ & $\begin{array}{c}\text { Scientific boundary work and } \\
\text { food regime transitions: the } \\
\text { double movement and the } \\
\text { science of food safety } \\
\text { regulation }\end{array}$ & 2017 & $\begin{array}{l}\text { Agriculture and } \\
\text { Human Values }\end{array}$ & Inglês & $\begin{array}{l}\text { Estados } \\
\text { Unidos }\end{array}$ & $\begin{array}{l}\text { Duplo } \\
\text { Movimento }\end{array}$ & Teórico & $\begin{array}{c}\text { Meio } \\
\text { Ambiente }\end{array}$ \\
\hline $\begin{array}{l}\text { RANDLES, } \\
\text { Sally; } \\
\text { DEWICK, } \\
\text { Paul; } \\
\text { LOVERIDGE } \\
\text {, Denis; } \\
\text { SCHMIDT, } \\
\text { Jan C. } \\
\end{array}$ & $\begin{array}{c}\text { Nano-worlds as } \\
\text { Schumpeterian emergence } \\
\text { and Polanyian double- } \\
\text { movements }\end{array}$ & 2008 & $\begin{array}{l}\text { Technology } \\
\text { Analysis \& } \\
\text { Strategic } \\
\text { Management }\end{array}$ & Inglês & $\begin{array}{c}\text { Estados } \\
\text { Unidos / } \\
\text { Reino Unido }\end{array}$ & $\begin{array}{c}\text { Duplo } \\
\text { Movimento }\end{array}$ & Teórico & Tecnologia \\
\hline $\begin{array}{l}\text { RANKIN, } \\
\text { Katharine } \\
\text { N. }\end{array}$ & $\begin{array}{c}\text { Manufacturing rural finance in } \\
\text { Asia: Institutional } \\
\text { assemblages, market } \\
\text { societies, entrepreneurial } \\
\text { subjects }\end{array}$ & 2008 & Geoforum & Inglês & Canadá & $\begin{array}{l}\text { História } \\
\text { Econômica }\end{array}$ & Aplicado & Rural \\
\hline $\begin{array}{l}\text { RIAIN, Seán } \\
\text { Ó. }\end{array}$ & $\begin{array}{l}\text { Time-space intensification: } \\
\text { Karl Polanyi, the double } \\
\text { movement, and global } \\
\text { informational capitalism }\end{array}$ & 2006 & $\begin{array}{l}\text { Theory and } \\
\text { Society }\end{array}$ & Inglês & Irlanda & $\begin{array}{l}\text { Duplo } \\
\text { Movimento }\end{array}$ & Aplicado & Tecnologia \\
\hline \begin{tabular}{|c|} 
RODRIGUE \\
S, Waldecy; \\
SANTOS, \\
Nayara \\
Silva. \\
\end{tabular} & $\begin{array}{c}\text { Desenvolvimento territorial } \\
\text { no Brasil: uma análise a partir } \\
\text { da concepção teórica de Karl } \\
\text { Polanyi }\end{array}$ & 2018 & Interações & Português & Brasil & $\begin{array}{l}\text { História } \\
\text { Econômica }\end{array}$ & Teórico & Econômico \\
\hline $\begin{array}{c}\text { RONCALLO, } \\
\text { Alejandra }\end{array}$ & $\begin{array}{c}\text { Cosmologies and } \\
\text { Regionalisms from 'Above' } \\
\text { and 'Below' in the post-cold } \\
\text { war Americas: the Relevance } \\
\text { of Karl Polanyi for the 21st } \\
\text { century }\end{array}$ & 2013 & $\begin{array}{l}\text { Third World } \\
\text { Quarterly }\end{array}$ & Inglês & $\begin{array}{l}\text { Estados } \\
\text { Unidos }\end{array}$ & $\begin{array}{c}\text { Duplo } \\
\text { Movimento }\end{array}$ & Teórico & $\begin{array}{c}\text { Meio } \\
\text { Ambiente }\end{array}$ \\
\hline $\begin{array}{c}\text { ROY, } \\
\text { Michael J; } \\
\text { HACKETT, } \\
\text { Michelle T. }\end{array}$ & $\begin{array}{c}\text { Polanyi's 'substantive } \\
\text { approach' to the economy in } \\
\text { action? Conceptualising social } \\
\text { enterprise as a public health } \\
\text { 'intervention' }\end{array}$ & 2017 & $\begin{array}{c}\text { Review of Social } \\
\text { Economy }\end{array}$ & Inglês & $\begin{array}{l}\text { Reino Unido } \\
\text { / Austrália }\end{array}$ & $\begin{array}{c}\text { Duplo } \\
\text { Movimento }\end{array}$ & Teórico & Saúde \\
\hline $\begin{array}{l}\text { SAHOO, } \\
\text { Sarbeswar }\end{array}$ & $\begin{array}{c}\text { Market Liberalism, } \\
\text { Marginalised Citizens and } \\
\text { Countermovements in India }\end{array}$ & 2017 & $\begin{array}{l}\text { Asian Studies } \\
\text { Review }\end{array}$ & Inglês & Índia & $\begin{array}{l}\text { Duplo } \\
\text { Movimento }\end{array}$ & Aplicado & Econômico \\
\hline $\begin{array}{l}\text { SAIAG, } \\
\text { Hadrien }\end{array}$ & $\begin{array}{c}\text { Towards a neo- Polanyian } \\
\text { approach to money: } \\
\text { integrating the concept of } \\
\text { debt }\end{array}$ & 2014 & $\begin{array}{l}\text { Economy and } \\
\text { Society }\end{array}$ & Inglês & França & Dinheiro & Teórico & Econômico \\
\hline
\end{tabular}




\begin{tabular}{|c|c|c|c|c|c|c|c|c|}
\hline AUTORIA & TíTULO & ANO & DIVULGAÇÃO & IDIOMA & $\begin{array}{l}\text { PAÍS DO } \\
\text { VÍNCULO }\end{array}$ & ABORDAGEM & ASPECTO & CATEGORIA \\
\hline $\begin{array}{c}\text { SANDBROO } \\
\text { K, Richard }\end{array}$ & $\begin{array}{c}\text { Polanyi and Post- } \\
\text { neoliberalism in the Global } \\
\text { South: Dilemmas of Re- } \\
\text { embedding the Economy }\end{array}$ & 2011 & $\begin{array}{l}\text { New Political } \\
\text { Economy }\end{array}$ & Inglês & Canadá & Enraizamento & Aplicado & Econômico \\
\hline \begin{tabular}{|l|} 
SCHNEIDER \\
, Sergio; \\
ESCHER, \\
Fabiano.
\end{tabular} & $\begin{array}{c}\text { A contribuição de Karl Polanyi } \\
\text { para a sociologia do } \\
\text { desenvolvimento rural }\end{array}$ & 2011 & Sociologias & Portuguès & Brasil & $\begin{array}{l}\text { História } \\
\text { Econômica }\end{array}$ & Teórico & Rural \\
\hline $\begin{array}{l}\text { SCOTT, } \\
\text { Alan }\end{array}$ & $\begin{array}{c}\text { Development Theory and the } \\
\text { Constitution of Market } \\
\text { Society: A Polanyian View }\end{array}$ & 2012 & $\begin{array}{l}\text { Comparative } \\
\text { Sociology }\end{array}$ & Inglês & Austrália & $\begin{array}{l}\text { História } \\
\text { Econômica }\end{array}$ & Teórico & Econômico \\
\hline $\begin{array}{l}\text { SCOTT, } \\
\text { Michael }\end{array}$ & $\begin{array}{c}\text { 'Hipster capitalism'in the age } \\
\text { of austerity? polanyi meets } \\
\text { bourdieu's new petite } \\
\text { bourgeoisie }\end{array}$ & 2017 & Cultural Sociology & Inglês & Austrália & $\begin{array}{l}\text { História } \\
\text { Econômica }\end{array}$ & Teórico & Sociedade \\
\hline $\begin{array}{l}\text { SEARCY, } \\
\text { Dennis R. }\end{array}$ & $\begin{array}{c}\text { Beyond the self-regulating } \\
\text { market in market society: a } \\
\text { critique of Polanyi's theory of } \\
\text { the state }\end{array}$ & 1993 & $\begin{array}{c}\text { Review of Social } \\
\text { Economy }\end{array}$ & Inglês & $\begin{array}{l}\text { Estados } \\
\text { Unidos }\end{array}$ & $\begin{array}{l}\text { História } \\
\text { Econômica }\end{array}$ & Teórico & Econômico \\
\hline $\begin{array}{c}\text { SERVET, } \\
\text { Jean-Michel }\end{array}$ & $\begin{array}{c}\text { Le principe de réciprocité } \\
\text { chez Karl Polanyi, } \\
\text { contribution à une définition } \\
\text { de l'économie solidaire }\end{array}$ & 2007 & $\begin{array}{l}\text { Revue tiers } \\
\text { monde }\end{array}$ & Francês & Suiça & $\begin{array}{l}\text { História } \\
\text { Econômica }\end{array}$ & Teórico & Econômico \\
\hline $\begin{array}{l}\text { SILVER, } \\
\text { Beverly; } \\
\text { ARRIGHI, } \\
\text { Giovanni. }\end{array}$ & $\begin{array}{c}\text { Polanyi's "double } \\
\text { movement": The belle } \\
\text { époques of British and US } \\
\text { hegemony compared }\end{array}$ & 2003 & Politics \& Society & Inglês & $\begin{array}{l}\text { Estados } \\
\text { Unidos }\end{array}$ & $\begin{array}{c}\text { Duplo } \\
\text { Movimento }\end{array}$ & Aplicado & Sociedade \\
\hline $\begin{array}{l}\text { ŠITERA, } \\
\text { Daniel }\end{array}$ & $\begin{array}{c}\text { The Polanyian Perspective } \\
\text { Meets the Varieties of } \\
\text { Capitalism: Inspecting the } \\
\text { Consequences of the } \\
\text { Institutional Changes in South } \\
\text { Korea since } 1997\end{array}$ & 2014 & Perspectives & Inglês & N.I. & $\begin{array}{c}\text { Duplo } \\
\text { Movimento }\end{array}$ & Aplicado & Econômico \\
\hline $\begin{array}{l}\text { SMITH, } \\
\text { Robert }\end{array}$ & $\begin{array}{c}\text { Reading Polanyi in Erbil: } \\
\text { understanding socio-political } \\
\text { factors in the development of } \\
\text { Iraqi Kurdistan }\end{array}$ & 2018 & Globalizations & Inglês & Reino Unido & $\begin{array}{l}\text { História } \\
\text { Econômica }\end{array}$ & Aplicado & Econômico \\
\hline $\begin{array}{l}\text { STEINER, } \\
\text { Philippe }\end{array}$ & $\begin{array}{l}\text { Who is right about the } \\
\text { modern economy: Polanyi, } \\
\text { Zelizer, or both? }\end{array}$ & 2009 & $\begin{array}{l}\text { Theory and } \\
\text { Society }\end{array}$ & Inglês & França & Dinheiro & Teórico & Econômico \\
\hline $\begin{array}{l}\text { STEWART, } \\
\text { Frances }\end{array}$ & $\begin{array}{l}\text { Power and Progress: The } \\
\text { Swing of the Pendulum }\end{array}$ & 2010 & \begin{tabular}{|c|} 
Journal of Human \\
Development and \\
Capabilities
\end{tabular} & Inglês & Reino Unido & $\begin{array}{c}\text { Duplo } \\
\text { Movimento }\end{array}$ & Teórico & Econômico \\
\hline $\begin{array}{l}\text { TRAINER, } \\
\text { Ted }\end{array}$ & $\begin{array}{c}\text { Understanding the Concept } \\
\text { of Development }\end{array}$ & 1996 & Humanomics, & Inglês & Austrália & $\begin{array}{c}\text { História } \\
\text { Econômica }\end{array}$ & Teórico & Econômico \\
\hline $\begin{array}{l}\text { VALDERRA } \\
\text { MA, Paula } \\
\text { S. }\end{array}$ & $\begin{array}{l}\text { Crisis del modelo neoliberal, } \\
\text { hacia una planificación } \\
\text { regional. Un aporte } \\
\text { polanyiano }\end{array}$ & 2014 & $\begin{array}{l}\text { Íconos Revista de } \\
\text { Ciencias Sociales }\end{array}$ & Esp. & Alemanha & $\begin{array}{l}\text { Planejamento } \\
\text { Regional }\end{array}$ & Teórico & Econômico \\
\hline $\begin{array}{l}\text { VOSSOLE, } \\
\text { Jonas V. }\end{array}$ & $\begin{array}{c}\text { A crise de legitimidade da } \\
\text { governança climática global. } \\
\text { Combinação de uma } \\
\text { perspetiva marxista e } \\
\text { polanyiana } \\
\end{array}$ & 2013 & $\begin{array}{l}\text { Revista Crítica de } \\
\text { Ciências Sociais }\end{array}$ & Português & Portugal & $\begin{array}{l}\text { Duplo } \\
\text { Movimento }\end{array}$ & Teórico & $\begin{array}{c}\text { Meio } \\
\text { Ambiente }\end{array}$ \\
\hline $\begin{array}{l}\text { WATSON, } \\
\text { Matthew }\end{array}$ & \begin{tabular}{|c|} 
The great transformation and \\
progressive possibilities: the \\
political limits of Polanyi's \\
Marxian history of economic \\
ideas \\
\end{tabular} & 2014 & $\begin{array}{l}\text { Economy and } \\
\text { Society }\end{array}$ & Inglês & Reino Unido & $\begin{array}{l}\text { História } \\
\text { Econômica }\end{array}$ & Teórico & Econômico \\
\hline $\begin{array}{l}\text { WOOD, } \\
\text { Ellen } \\
\text { Meiksins }\end{array}$ & $\begin{array}{c}\text { From Opportunity to } \\
\text { Imperative: The History of the } \\
\text { Market }\end{array}$ & 1994 & Monthly Review & Inglês & Canadá & $\begin{array}{l}\text { História } \\
\text { Econômica }\end{array}$ & Teórico & Econômico \\
\hline $\begin{array}{l}\text { WORTH, } \\
\text { Owen }\end{array}$ & Reviving Hayek's dream & 2017 & Globalizations & Inglês & Irlanda & $\begin{array}{c}\text { Duplo } \\
\text { Movimento }\end{array}$ & Aplicado & Econômico \\
\hline
\end{tabular}

Isso coadunou com a necessidade da seleção inicial realizada para busca do material desejado, visto que os materiais que atenderam aos quesitos básicos do protocolo foram listados, e, uma vez listados, os trabalhos são postos ao crivo dos critérios de inclusão e exclusão, sendo que os resultados desse estágio devem ser registrados. 
Superada a seleção, deve ser iniciado o processo de extração das informações contidas nos trabalhos. Para isso, a utilização de formulários adequados à pesquisa é ferramenta indispensável.

\section{Resultados e discussões}

\subsection{Análise bibliométrica da produção científica nacional e internacional em desenvolvimento e território com base no pensamento de Karl Polanyi}

Cumpridas as etapas descritas alhures, todos os instrumentos e materiais estão postos para início do processo de avaliação dos trabalhos. Para isso, a produção de sínteses auxilia na descrição objetiva dos trabalhos, mostrando os temas abordados e seus aspectos específicos. (KITCHENHAM, 2004).

Para a identificar os conceitos de Karl Polanyi trabalhados, foi utilizada a busca por palavras referentes ao tema no texto, por exemplo, para identificar os trabalhos que articulam a ideia do duplo movimento de Karl Polanyi foi buscada pela palavra 'duplo' nos idiomas dos textos. Uma vez identificada a palavra do tema, o arquivo era separado para análise mais completa para verificar se tratava efetivamente do conceito utilizado por Karl Polanyi.

Todavia, cabe destacar que a análise de aspectos mais gerais como a história econômica e o enraizamento, por serem abordados de forma mais ampla, não seguiram as mesmas formas de trabalho que o território e o duplo movimento, todavia, não acreditando haver prejuízo ao presente trabalho em razão disso. Inclusive por haver dificuldade em delimitar palavras de busca para temas tão amplos, vez que, por exemplo, a história econômica pode ser aplicada na análise de múltiplos objetos.

Um dos primeiros elementos utilizados para catalogar os trabalhos foi a nacionalidade dos vínculos dos autores. Como a identificação acadêmica é praxe nas publicações científicas, a indicação do país de origem da instituição do vínculo se fez possível.

Tabela 1. Nacionalidade dos Vínculos Institucionais dos Autores

\begin{tabular}{cc}
\hline País & Quantidade de Trabalhos \\
\hline Estados Unidos & 25 \\
\hline Reino Unido & 19 \\
\hline Austrália & 10 \\
\hline Canadá & 8 \\
\hline Irlanda & 6 \\
\hline Alemanha; Itália & 4 \\
\hline Brasil & 3 \\
\hline França; México; Turquia & 2 \\
\hline $\begin{array}{c}\text { África do Sul; Áustria; Bélgica; Chile; Espanha; } \\
\text { Chilipinas; Holanda; Índia; Israel; Portugal; República }\end{array}$ \\
\hline Total Senegal; Sérvia; Singapura; Suíça
\end{tabular}


Ademais, dos 26 (vinte e seis) países identificados pelo vínculo institucional, que possuem mais de 15 (quinze) idiomas oficiais, 86\% (oitenta e seis porcento) de todas as publicações estão no idioma inglês.

Tabela 2. Idiomas dos Trabalhos Encontrados na Revisão Sistemática

\begin{tabular}{ccc}
\hline Idioma & Quantidade de Trabalhos & Porcentagem \\
\hline Inglês & 82 & $86,3 \%$ \\
\hline Espanhol & 6 & $6,3 \%$ \\
\hline Português & 3 & $3,2 \%$ \\
\hline Francês & 2 & $2,1 \%$ \\
\hline Alemão & 1 & $1,1 \%$ \\
\hline Sérvio & 1 & $1,1 \%$ \\
\hline
\end{tabular}

Quanto às datas das publicações, a primeira data de 1990, desde então o número de publicações anuais tem crescido significativamente, saindo de uma média de dezesseis publicações de 1990-2001, para trinta e seis de 2002-2011, e quarenta e seis de 2012-2018.

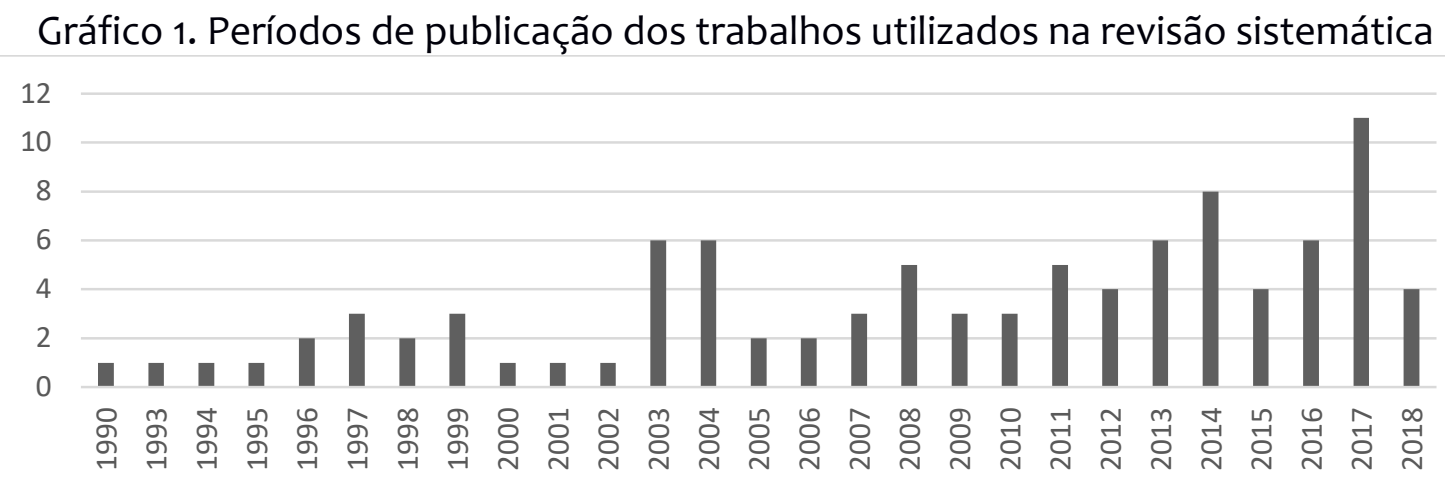

Quanto aos aspectos dos trabalhos que abordam as obras de Karl Polanyi, é possível identificar dois grandes grupos, aqui classificados pelos autores da presente revisão sistemática em "aplicado" e "teórico".

Tabela 3. Características dos trabalhos utilizados na revisão sistemática

\begin{tabular}{ccc}
\hline Aspecto & Quantidade de Trabalhos & Porcentagem \\
\hline Teórico & 76 & $80 \%$ \\
\hline Aplicado & 19 & $20 \%$ \\
\hline
\end{tabular}

No que tange às ideias de Polanyi articuladas nos trabalhos, identificou-se quatro principais assuntos abordados pelos autores, a saber, dinheiro, duplo movimento, enraizamento, e história econômica. 
Tabela 4. Ideias de Karl Polanyi nos Trabalhos Utilizados na Revisão Sistemática

\begin{tabular}{ccc}
\hline Abordagem & Quantidade de Trabalhos & Porcentagem \\
\hline História Econômica & 45 & $47,4 \%$ \\
\hline Duplo Movimento & 28 & $29,5 \%$ \\
\hline Enraizamento & 14 & $14,7 \%$ \\
\hline Dinheiro & 4 & $4,2 \%$ \\
\hline Outros & 4 & $4,2 \%$ \\
\hline
\end{tabular}

Destaca-se que dos trabalhos com aspecto dominantemente "aplicado", 12 (doze) utilizam a abordagem do Duplo Movimento de Polanyi. Ademais, na catalogação dos trabalhos, houve a categorização dos assuntos dominantes nos textos em: Econômico, Sociedade, Gênero, Meio Ambiente, Político, Rural, Saúde, Tecnologia.

Tabela 5. Categorias dos Trabalhos Utilizados na Revisão Sistemática.

\begin{tabular}{ccc}
\hline Categoria & Quantidade de Trabalhos & Porcentagem \\
\hline Econômico & 51 & $53,7 \%$ \\
\hline Sociedade ${ }^{1}$ & 24 & $25,3 \%$ \\
\hline Meio Ambiente & 10 & $10,5 \%$ \\
\hline Tecnologia & 3 & $3,2 \%$ \\
\hline Rural & 3 & $3,2 \%$ \\
\hline Saúde & 2 & $2,1 \%$ \\
\hline Político & 1 & $1,1 \%$ \\
\hline Gênero & 1 & $1,1 \%$
\end{tabular}

Por fim, ante aos dados expostos, respondendo à pergunta norteadora desta revisão - identificar publicações envolvendo desenvolvimento e território que trabalhem a obra de Karl Polanyi de modo central nas discussões - é possível dizer que maior parte dos trabalhos que abordam Karl Polanyi na perspectiva proposta possuem um aspecto teórico (86\%) e em sua maioria (76\%) trabalham o duplo movimento e a história econômica proposta por Karl Polanyi, tendo um caráter econômico em $53,6 \%$ das publicações.

\subsection{Desenvolvimento e território em Karl Polanyi: principais pesquisas na literatura internacional}

Diante dos textos encontrados na revisão sistemática, seguindo o protocolo da revisão, todos os textos foram lidos para confecção de sínteses que expusessem as principais abordagens realizadas a partir das ideias de Karl Polanyi. É nesse sentido que seguem descritos os textos que trabalham a perspectiva de desenvolvimento e território nas bases do pensamento de Karl Polanyi.

\footnotetext{
1 Todavia, destaca-se dos temas pautados a classificação "Sociedade", isso porque quando se trabalha com uma grande diversidade de trabalhos, classificá-los individualmente torna-se inviável e de pouco interesse para a revisão sistemática, vez de que essa busca uma visão macro do cenário posto. Exemplo disso, observa-se que o aspecto "Político" e "Gênero" tiveram apenas um trabalho classificado para cada um, porém, se o mesmo fosse feito para os demais, exigiria a criação de temáticas que fugiriam da área acadêmica das ciências humanas, sociais e sociais aplicadas, o que não é de todo interessante para a presente revisão sistemática.
} 
O intuito foi verificar quais as principais publicações sobre desenvolvimento e território que utilizaram categorias conceituais originais do pensamento de Karl Polanyi, como as pesquisas, em diferentes países, vêm sendo desenvolvidas utilizando as concepções teóricas de Karl Polanyi em distintas abordagens, tudo isso para conhecer e provocar novas agendas de investigação a partir desta interação complexa entre economia e sociedade, parte de central do pensamento polanyiano.

A pergunta central é se é possível e em que medida o pensamento de Karl Polanyi pode ajudar a refletir sobre a relação entre desenvolvimento e território? Assim, pode-se descrever como a produção científica em escala internacional capturou e trabalhou estas categorias originárias de Karl Polanyi aplicadas a temas relacionados a desenvolvimento e seus rebatimentos territoriais.

Ao nosso ver, a preocupação central de Karl Polanyi era muito mais associada a perspectiva geopolítica do desenvolvimento em termos globais e nacionais, do que propriamente tinha preocupação em uma dimensão territorial mais compartimentada e localizada. No entanto, sua perspectiva metodológica, associada principalmente na percepção dos mecanismos da autoproteção da sociedade e a heterogeneidade do tecido social, pode contribuir a pensar temas específicos para a agenda do desenvolvimento regional e territorial, como, por exemplo, a questão alimentar, meio ambiente, cooperativismo, assistência social, saúde pública, populações tradicionais, populações com deficiência, dentre outras agendas relevantes para uma visão sistêmica e interdisciplinar do desenvolvimento.

Partindo inicialmente de uma perspectiva territorial e geopolítica mais ampliada, Riain (2006) analisou a intensificação do espaço-tempo no capitalismo atual pela perspectiva polanyiana do duplo movimento. Essa ideia é posta na análise entre as pressões pela compressão do espaço-tempo e os esforços dos trabalhadores, firmas e Estados no enraizamento de novas formas de espaço-tempo como forma de proteção contra as pressões.

Já o trabalho de Fraser (2014) expos que Karl Polanyi talvez tenha identificado um dos grandes pontos-cegos da perspectiva de desenvolvimento, ele identificou o Estado moderno como principal agente de proteção social, sendo também que Karl Polanyi compreendia que as capacidades regulatórias dos Estados dependiam de arranjos internacionais, por isso, ele rejeitou as primeiras propostas de regimes de livre mercado do século XX que desproveriam os Estados europeus do controle monetário e da adoção de políticas de pleno emprego. Desse modo, Karl Polanyi advogava pelo controle estatal da moeda nacional que facilitaria medidas protetivas em nível nacional.

Nessa mesma perspectiva crítica ao neoliberalismo, Valderrama (2014) analisou a saída de potências industrializadas da América Latina e expos o surgimento de alternativas políticas nessa região. Em sua análise teórica do contexto político econômico da região, a autora utilizou a ideia de duplo movimento posta por Karl Polanyi para expor que a criação de um mercado autorregulado é impossível porque o mero intento de instaurá-lo geraria um contramovimento de oposição social. Além disso, a autora ainda discute a participação do Estado em ações ambíguas diante do capitalismo neoliberal, onde o Estado precisa, por exemplo, arcar com gastos sociais para evitar ações de contramovimento. Alegando também que a crise do Estado neoliberal se observa tanto na União Europeia quanto nos Estados Unidos, onde a rigidez do mercado de 
trabalho, fruto de um contramovimento de proteção social, não permitiu ajustes adequados e provocou desequilíbrios.

Guthman (2007) e Kim (2010) apresentaram trabalhos de inspiração polanyiana para explicar a trajetória neoliberal da Coréia do Sul e a relação entre o com o duplo movimento de Karl Polanyi. Foi exposto especialmente por Kim (2010) que o rápido processo de neoliberalização que ocorreu na Coréia do Sul devastou o aparato desenvolvimentista estatal, ademais, criando o desenraizamento da economia ante ao livre mercado associado ao alto risco socioeconômico, o que gerou contramovimentos de proteção da sociedade, materializados nas diversas greves e paralizações ocorridas desde 1997 naquele país.

Outros trabalhos muito interessantes na perspectiva polanyiana acerca dos efeitos do neoliberalismo sobre a economias nacionais, são de Cuadra (2015) que analisou a relação entre Estado e mercado em um contexto histórico, tomando como objeto o México entre 1940 e 1980. Sahoo (2017) que analisou os impactos do neoliberalismo na economia da Índia, apresentando os contramovimentos existentes na busca de autoproteção da sociedade, onde grupos civis que atuam no duplo movimento foram impactados pelas transformações neoliberais da economia. Worth (2017) que expos o conceito de duplo movimento de Karl Polanyi e o articulou a movimentos como o Brexit, a ascensão da extrema direita pela Europa, a vitória de Donald Trump, além do extremismo religioso. Em um trabalho muito interessante, Smith (2018) analisou o surgimento do Governo Regional Curdo após o caos do Iraque pós-Saddam, onde a partir da ideia de duplo movimento de Karl Polanyi apontou que no mundo Árabe a dinâmica é distinta, pois as estruturas do Estados trazem o poder ao centro, logo, o contramovimento de autoproteção social na sociedade resta prejudicado.

Uma outra agenda de pesquisa bem trabalhada por autores polanyianos no cenário científico internacional está relacionada a questão do desenvolvimento rural e das contradições capitalistas no espaço rural a partir da transformação pelo processo de comoditização para o mercado internacional. Altvater e Mahnkopf (1997) trabalharam com o aspecto do desenraizamento ao dinheiro e da terra em razão do processo de comoditização, onde defendem que pensar o mercado sem commodities é completamente impensável, mas pensar o dinheiro sem commodities o é mais ainda, exemplo disso, expõem-se que dinheiro em conjunto com combustíveis fosseis catapultou a "grande transformação" em um nível global, estimulando o surgimento e crescimento de um sistema financeiro global como uma esfera monetária descolada da economia real, com várias consequências sociais e ambientais negativas sobre os territórios.

Já Cotula (2013) em análise da proteção e facilitação de investimentos ante à reestruturação das relações globais com a propriedade da terra, utilizou o mesmo conceito de território posto por Karl Polanyi, vez que remonta ao conceito clássico de território e sua relação com a soberania, em discussão sobre enraizamento e mercantilização das relações com a terra. Nesse sentido, o autor apontou para as leis de investimento que facilitam a aquisição de direitos à terra por investidores estrangeiros, muitas vezes por tratados de investimentos que reforçam a permissão do acesso à terra por investimentos estrangeiros, todavia, relembrando que, amparado no Direito internacional, os Estados possuem soberania para regular a admissão de investimentos estrangeiros em seus territórios. 
Guthman (2007) discutiu a inserção de rótulos não exigidos por lei em produtos, em referências como produção livre de agrotóxicos, ou referências territoriais, ou em condições específicas de produção, em paralelo a discussão de Karl Polanyi sobre o duplo movimento. Assim, ocorrendo a análise de que esse processo de identificar produtos com características especiais além da simples mercadoria padrão oferecida no mercado é reflexo de um contramovimento da sociedade em busca de sua autodefesa.

Rankin (2008) analisou especificamente a formação de mercados mediada por instituições, tomando por objeto de estudo a financeirização rural no Nepal e no Vietnã. Em suas análises sobre isso, a autora utiliza a ideia de duplo movimento de Karl Polanyi para expor que a formação de mercados deve ser estruturada para atender aos grupos sociais do Estado que farão parte dessa formação do mercado, pois, se não houver isso de uma forma estruturada e estratégica, movimentos inevitáveis de contramovimento para proteção contra os custos sociais irão surgir.

Os autores brasileiros Schneider e Escher (2011) trabalharam o aspecto territorial em abordagem ao conceito de duplo movimento de Karl Polanyi, sendo o território analisado nas transformações ocorridas no cenário econômico e rural. Exemplo disso é a exposição de que os territórios são espaços de congeminação entre as perspectivas locais, regionais e globais. Sobre as transformações até então vislumbradas pelos autores, argumenta-se que os aspectos territoriais dos espaços influem na dinâmica das políticas públicas e nas próprias formas de funcionamento das instituições. Ademais, argumentam que, diante do confronto com mercados, é possível a criação de espaços de enraizamento das relações sociais como fator de competitividade territorial, para isso, integrando as economias dos territórios por meio de mecanismos alternativos de distribuição e consumo da produção.

Hough e Bair (2012) analisaram a relação com a terra e o sistema produtivo na Colômbia, apresentando a constituição de grupos como Movimento dos Trabalhadores Rurais Sem Terra (MST), Via Campesina, e Exército Zapatista de Libertação Nacional (EZLN), como parte do processo de contramovimento (ou duplo movimento) de proteção da sociedade ante o mercado, ideia exposta por Karl Polanyi. Já Carrol (2016) analisou o processo de desenvolvimento da produção de organismos geneticamente modificados e a participação da sociedade na regulação desse processo, tendo como um dos pontos de discussão a ideia do duplo movimento posta por Karl Polanyi, onde, no caso em análise, é construída a argumentação de que a regulação de organismos que podem gerar dano à sociedade é passível de ser entendida como uma autoproteção da sociedade diante do mercado.

Quark e Lienesch (2016) analisaram a transição de regimes alimentares em justaposição aos limites científicos e sua regulação. A ideia do duplo movimento de Karl Polanyi é articulada com o argumento de que a transição de um regime para o outro é conduzida por um conflito social nos termos do descrito por Karl Polanyi no duplo movimento, vez que há uma luta interestatal pela hegemonia no sistema agroalimentar, com movimentos sociais desafiando a legitimidade de sistemas alimentares que privilegiam o mercado liberal e empresas capitalistas em sentido contrário. Já Graddy-Lovelace e Diamond (2017) analisaram o histórico dos subsídios à produção agrícola dos Estados Unidos em justaposição ao conceito do duplo movimento de Karl Polanyi, apontando a relação entre a autoproteção da 
sociedade ante ao livre mercado como representação das medidas protetivas em formas de subsídios aos produtores rurais.

Uma outra agenda de pesquisa identificada em trabalhos científicos de inspiração polanyiana tem relação com questão ambiental, em especial relacionada com as transformações no território causadas pelo processo de acumulação capitalista, seus rebatimentos geopolíticos, e os mecanismos de autoproteção que vem sendo desenvolvidos em diversas escalas territoriais. Roncallo (2013) utilizou o conceito de duplo movimento de Karl Polanyi para discutir o conflito entre a forma como ocidentais e indígenas vêm e interagem com o espaço, apontando os movimentos contra hegemônicos dos indígenas na busca da manutenção de sua visão de mundo.

Pearse (2014) utilizou o conceito de duplo movimento de Karl Polanyi na análise de movimentos sociais no que tange à relação entre clima e energia. Apontando os movimentos sociais como ações de contramovimento de defesa da sociedade e do meio ambiente. Mcgee e Steffek (2016) utilizaram o conceito de duplo movimento de Karl Polanyi como um dos instrumentos de análise da mudança na governança climática global a partir da conferência do clima em Copenhagen.

Em um dos aspectos em que é abordado o duplo movimento em relação à mudança exposta, é posto que países em desenvolvimento se tornaram locais de resistência à ordem econômica internacional dominante no período pós-guerra, adotando agenda política denominada multilateralismo redistributivo, que tem como um de seus focos a transferência de recursos de países desenvolvidos para países em desenvolvimento, sendo isso entendido pelos autores como um contramovimento ao mercado auto regulado em nível internacional. Benites-Lazaro e Mello-Théry (2017) analisaram a responsabilidade social corporativa em relação com o mercado de carbono na América Latina. É defendido que esse mecanismo de responsabilidade social age como um duplo movimento de proteção contra as externalidades do mercado, gerando ações que atendem ao interesse público.

Por fim, existe um grupo de contribuições científicas de autores polanyianos relacionadas à razão substantiva, economia plural e a própria agenda do desenvolvimento territorial. Fontan (2008) analisou a relação entre desenvolvimento territorial e inovação social, aplicando as ideias de Karl Polanyi sobre o processo de institucionalização das atividades sociais e do duplo movimento. A perspectiva territorial adotada pelo autor perpassa tanto o conceito clássico de território quanto definições modernas do espaço delimitado em suas esferas políticas, econômicas e culturais. ROY e HACKETT (2016) analisaram o comportamento das empresas que possuem caráter social, almejando lucro, mas também com objetivos sociais, com o conceito de duplo movimento de Karl Polanyi, expondo que essa modalidade de empresas são uma resposta à mercantilização.

Uma relevante contribuição para a aplicação do pensamento Karl Polanyi no desenvolvimento territorial foi dada por Rodrigues e Santos (2018) no artigo 'Desenvolvimento territorial no Brasil: uma análise a partir da concepção teórica de Karl Polanyi'. Os autores articulam a ideia de Karl Polanyi da economia substantiva em justaposição ao conceito de economia plural, reforçando essas características em relação aos processos de desenvolvimento econômico de esfera territorial. 
Sendo essa característica territorial, articulada com o conceito de desenvolvimento, posta nas abordagens para análise de projetos e paradigmas. Além disso, os autores criaram um índice nacional que mediu os níveis de economia plural nos municípios brasileiros a partir de uma perspectiva teórica de Karl Polanyi. Concluíram que os municípios com maior prevalência de estruturas autoprotetoras são aqueles com maior qualidade de vida.

\section{Considerações Finais}

Diante da sistematização dos trabalhos que articulam as ideias de Karl Polanyi, os pesquisadores poderão encontrar neste artigo fonte para novas pesquisas e abordagem dos conceitos utilizados por esse teórico social que apresentou um arcabouço de teorias que fornecem uma visão outsider das instituições sociais, entre elas o território e o desenvolvimento.

Sendo nesse sentido da abordagem territorial que advoga Fraser, 2014, conforme exposto alhures, indicando que uma das principais contribuições de Karl Polanyi para o estudo do desenvolvimento foi compreender o papel do Estado como agente de proteção da sociedade e fomentador do desenvolvimento. Essa visão que também é corroborada por Cotula, 2013, que aponta a relação do mercado com o território em termos de acesso à terra, indicando os efeitos degenerativos do processo de mercantilização do meio ambiente, indicando o papel do Estado como instituição política com poder de ordenamento do território para promoção do desenvolvimento nos termos polanyianos.

Por outro lado, as mudanças para o desenvolvimento de qualquer território acabam por se defrontar com a ideia do duplo movimento polanyiano (POLANYI, 2012a), vez que as buscas por mudanças, sejam liberais ou protecionistas, acabam por gerar forças em sentido oposto, assim, causando deformidades nos processos e nas relações socioeconômicas. Sendo nesse sentido que argumentam Schneider e Escher, 2011, apontando alternativas, em vias de movimento pendular do duplo movimento, ante a expansão liberal da economia, para o enraizamento das relações sociais como promotor de competitividade territorial a partir da integração regional dos processos de distribuição e consumo da produção por meios alternativos.

O duplo movimento polanyiano também explica o surgimento de grupos de movimentos sociais e da sociedade civil organizada, exemplo desse movimento de busca por proteção na perspectiva polanyiana pode ser encontrado no trabalho de Phillip Hough e Jennifer Bair, 2012, em que os autores vêm movimentos como Via Campesina, Trabalhadores Rurais Sem Terra, e Exército Zapatista de Libertação Nacional, como uma resposta às políticas voltadas à mercantilização da vida e do território. Assim, cabendo aos tomadores de decisão e formuladores de políticas públicas analisarem suas propostas e os movimentos pendulares que agirão como contramovimento, antes de executarem seus projetos.

Outrossim, pela abordagem do desarraigamento - antítese da ideia de enraizamento - vinculada ao processo de desenvolvimento do território, Elma Altvater e Birgit Mahnkopf, 1997, apontam que pensar o mercado sem mercadorias é absurdo, inclusive articulando que foram os combustíveis fósseis que catapultaram a grande transformação polanyiana a um nível global, que estimulou o surgimento de um sistema financeiro global descolado da economia real, assim, 
vinculando os processos mais sofisticados em termos de complexidade econômica ao mais simples, a própria existência do espaço e da natureza. Todavia, também lançando luz a uma mudança no planejamento de economias regionais, vez que, ante a complexidade dos mercados financeiros, as fronteiras dos territórios passam a ser defendidas nos balcões das bolsas de valores e nas redes onde operam os bancos.

Sendo esse processo de enraizamento/desarraigamento, articulado com o duplo movimento, amparado em uma perspectiva histórica que envolvem abordagens sociológicas e antropológicas, os pontos chave na obra de Karl Polanyi. Esse arcabouço teórico fornece uma rede de possibilidades para interpretação das situações fáticas das sociedades contemporâneas, principalmente quando o mercado participa como ator.

Esses apontamentos refletem o conteúdo encontrado por esta revisão sistemática. Ao início dos trabalhos não se vislumbrava as abordagens polanyianas em tantas perspectivas e dimensões, todavia, foi possível constituir uma big picture do cenário atual dos trabalhos esteados no desenvolvimento econômico e territorial de Karl Polanyi.

\section{REFERÊNCIAS}

ALTVATER, Elmar; MAHNKOPF, Birgit. The world market unbound. Review of International Political Economy, v. 4, n. 3, p. 448-471, 1997.

BAUMAN, Zygmunt. Liquid Times: Living in an age of uncertainty. Malden: Polity Press, 2017.

BENITES-LAZARO, Lira Luz; MELLO-THÉRY, Neli Aparecida. CSR as a legitimatizing tool in carbon market: Evidence from Latin America's Clean Development Mechanism. Journal of cleaner production, v. 149, p. 218-226, 2017.

BIRCHFIELD, Vicki. Contesting the hegemony of market ideology: Gramsci's' good sense'and Polanyi's' double movement'. Review of International Political Economy, v. 6, n. 1, p. 27-54, 1999.

BLYTH, Mark. The great transformation in understanding Polanyi: Reply to Hejeebu and Mccloskey. Critical Review, v. 16, n. 1, p. 117-133, 2004.

CARROLL, Myles. The new agrarian double movement: hegemony and resistance in the GMO food economy. Review of International Political Economy, v. 23, n. 1, p. 128, 2016.

COTULA, Lorenzo. The New Enclosures? Polanyi, international investment law and the global land rush. Third World Quarterly, v. 34, n. 9, p. 1605-1629, 2013. 
CRAIG, David; PORTER, Doug. The third way and the third world: poverty reduction and social inclusion strategies in the rise of 'inclusive'liberalism. Review of International Political Economy, v. 12, n. 2, p. 226-263, 2005.

CUADRA, Héctor. Polanyi mestizo. Una interpretación de los procesos sociales de Estado y mercado en México. Revista mexicana de ciencias políticas y sociales, v. 60, n. 224, p. 133-162, 2015.

DALE, Gareth. Karl Polanyi: The limits of the market. Cambridge: Polity Press, 2010.

DODD, Steven. Orientating disability studies to disablist austerity: applying Fraser's insights. Disability \& Society, v. 31, n. 2, p. 149-165, 2016.

FELIZARDO, Katia. R.; MARTINS, Rafael. M. Engenharia de Software Experimental: Revisão Sistemática. São Carlos. 2015.

FONTAN, Jean-Marc. Développement territorial et innovation sociale: l'apport polanyien. Revue Interventions économiques. Papers in Political Economy, n. 38, 2008.

FRASER, Nancy. Can society be commodities all the way down? Post-Polanyian reflections on capitalist crisis. Economy and Society, v. 43, n. 4, p. 541-558, 2014

GOODWIN, Geoff. Rethinking the double movement: expanding the frontiers of Polanyian analysis in the Global South. Development and Change, v. 49, n. 5, p. 12681291, 2018.

GOTTMANN, Jean. The significance of territory. Univ of Virginia Pr, 1973.

GRADDY-LOVELACE, Garrett; DIAMOND, Adam. From supply management to agricultural subsidies_and back again? The US Farm Bill \& agrarian (in) viability. Journal of rural studies, v. 50, p. 70-83, 2017.

GUTHMAN, Julie. The Polanyian way? Voluntary food labels as neoliberal governance. Antipode, v. 39, n. 3, p. 456-478, 2007.

HOLMES, Christopher. 'Whatever it takes': Polanyian perspectives on the eurozone crisis and the gold standard. Economy and Society, v. 43, n. 4, p. 582-602, 2014.

HÖPNER, Martin; SCHÄFER, Armin. Embeddedness and regional integration: waiting for Polanyi in a Hayekian setting. International Organization, v. 66, n. 3, p. 429-455, 2012.

HOUGH, Phillip A.; BAIR, Jennifer. Dispossession, Class Formation, and the Political Imaginary of Colombia's Coffee Producers over the Longue Duree: Beyond the Polanyian Analytic. Journal of World-Systems Research, v. 18, n. 1, p. 30-49, 2012. 
JESSON, Jill.; MATHESON, Lydia; LACEY, Fiona M. Doing your literature review: Traditional and systematic techniques. London: Sage, 2011.

KIM, Wonik. Simultaneous transitions: Democratization, neoliberalization, and possibilities for class compromise in South Korea. Review of Radical Political Economics, v. 42, n. 4, p. 505-527, 2010.

KITCHENHAM, Barbara. Procedures for performing systematic reviews. Keele, UK, Keele University, v. 33, n. 2004, p. 1-26, 2004.

MCGEE, Jeffrey; STEFFEK, Jens. The Copenhagen turn in global climate governance and the contentious history of differentiation in international law. Journal of Environmental Law, v. 28, n. 1, p. 37-63, 2016.

MCMICHAEL, Philip. Rethinking globalization: The agrarian question revisited. Review of International Political Economy, v. 4, n. 4, p. 630-662, 1997.

PEARSE, Rebecca. Moving targets: Carbon pricing, energy markets, and social movements in Australia. Environmental politics, v. 25, n. 6, p. 1079-1101, 2016.

PETTICREW, Mark.; ROBERTS, Helen. Systematic reviews in the social sciences: A practical guide. Malden: Blackwell Publishing, 2006.

POLANYI, Karl. Universal Capitalism or Regional Planning?. The London Quarterly of World Affairs, v. 10, n. 3, p. 86-91, 1945.

POLANYI, Karl. Our Obsolete Market Mentality. Commentary, v. 3, n. 2, p. 109-117, 1947.

POLANYI, Karl. A Grande Transformação. Rio de Janeiro: Elsevier, $2012 a$.

POLANYI, Karl. A subsistência do homem e ensaios correlatos. Rio de Janeiro: Contraponto, 2012b.

POLANYI, Karl. For a New West: Essays, 1919-1958. Malden: Polity Press, 2014.

POLANYI, Karl; ARENSBERG, Conrad. M.; PEARSON, Harry. W. Trade and Market in the Early Empires: economies in history and theory. Glencoe: The Free Press, 1957.

QUARK, Amy A.; LIENESCH, Rachel. Scientific boundary work and food regime transitions: the double movement and the science of food safety regulation.

Agriculture and Human Values, v. 34, n. 3, p. 645-661, 2017.

RANKIN, Katharine N. Manufacturing rural finance in Asia: Institutional assemblages, market societies, entrepreneurial subjects. Geoforum, v. 39, n. 6, p. 1965-1977, 2008. 
RIAIN, Seán Ó. Time-space intensification: Karl Polanyi, the double movement, and global informational capitalism. Theory and society, v. 35, n. 5-6, p. 507-528, 2006.

RODRIGUES, Waldecy; SANTOS, Nayara Silva. Karl Polanyi e o desenvolvimento econômico: um novo olhar sobre o regional / local? Revista de Desenvolvimento Econômico - RDE - Ano XIX - V. 1 - N. 36, Salvador, BA - p. 168 - 190, abril de 2017.

RODRIGUES, Waldecy; SANTOS, Nayara Silva. Desenvolvimento territorial no Brasil: uma análise a partir da concepção teórica de Karl Polanyi. Interações, v. 19, n. 1, p. 119-135, 2018.

RONCALLO, Alejandra. Cosmologies and Regionalisms from 'Above'and 'Below'in the post-cold war Americas: the Relevance of Karl Polanyi for the 21st century. Third World Quarterly, v. 34, n. 7, p. 1145-1158, 2013.

ROY, Michael J.; HACKETT, Michelle T. Polanyi's 'substantive approach'to the economy in action? Conceptualising social enterprise as a public health 'intervention'. Review of Social Economy, v. 75, n. 2, p. 89-111, 2017.

SAHOO, Sarbeswar. Market Liberalism, Marginalised Citizens and Countermovements in India. Asian Studies Review, v. 41, n. 1, p. 1-19, 2017.

SAIAG, Hadrien. Towards a neo-Polanyian approach to money: integrating the concept of debt. Economy and Society, v. 43, n. 4, p. 559-581, 2014.

SANDBROOK, Richard. Polanyi and Post-neoliberalism in the Global South: Dilemmas of Re-embedding the Economy. New Political Economy, v. 16, n. 4, p. 415443, 2011.

SCHNEIDER, Sergio; ESCHER, Fabiano. A contribuição de Karl Polanyi para a sociologia do desenvolvimento rural. Sociologias, v. 13, n. 27, p. 180-219, 2011.

SILVER, Beverly J.; ARRIGHI, Giovanni. Polanyi's “double movement”: The belle époques of British and US hegemony compared. Politics \& Society, v. 31, n. 2, p. 325$355,2003$.

ŠITERA, Daniel. The Polanyian Perspective Meets the Varieties of Capitalism: Inspecting the Consequences of the Institutional Changes in South Korea since 1997. Perspectives, v. 22, n. 1, p. 77-102, 2014.

SMITH, Robert. Reading Polanyi in Erbil: understanding socio-political factors in the development of Iraqi Kurdistan. Globalizations, v. 15, n. 7, p. 1045-1057, 2018.

TORGERSON, Carole. Systematic Reviews. London: Continuum, 2003. 
VALDERRAMA, Paula S. Crisis del modelo neoliberal, hacia una planificación regional: un aporte polanyiano. Íconos Revista de Ciencias Sociales, v.18, n. 1, p. 139153, 2014.

WORTH, Owen. Reviving Hayek's dream. Globalizations, v. 14, n. 1, p. 104-109, 2017.

Waldecy Rodrigues. Pós Doutor em Economia (UnB). Professor do Programa de Pós-Graduação em Desenvolvimento Regional da Universidade Federal do Tocantins.E-mail:waldecy@terra.com.br

Wainesten Camargo. Bacharel em Direito - Universidade Federal do Tocantins (UFT). Mestre em Desenvolvimento Regional - UFT. E-mail: wainesten@uft.edu.br

Como citar: RODRIGUES, Waldecy; CAMARGO, Wainesten. Território e Desenvolvimento em Karl Polanyi: uma revisão sistemática. Redes (St. Cruz Sul, Online), Santa Cruz do Sul, v. 25, p. 1764-1786, nov. 2020. ISSN 1982-6745. Disponível em: doi:https://doi.org/10.17058/redes.v25i4.14385.

\section{CONTRIBUIÇÃO DE CADA AUTOR}

a. Fundamentação teórico-conceitual e problematização: Waldecy Rodrigues

b. Pesquisa de dados e análise estatística: Waldecy Rodrigues

c. Elaboração de figuras e tabelas: Waldecy Rodrigues

d. Fotos:

e. Elaboração e redação do texto: Wainesten Camargo

f. Seleção das referências bibliográficas: Wainesten Camargo

Fontes de financiamento: Coordenação de Aperfeiçoamento de Pessoal de Nível Superior (Capes). 